\title{
Review on In Situ Acoustic Emission Monitoring in the Context of Structural Health Monitoring in Mines
}

\author{
Gerd Manthei ${ }^{1, *}$ and Katrin Plenkers ${ }^{2}$ (B) \\ 1 Department of Mechanical and Energy Engineering, THM University of Applied Sciences, \\ D-35390 Gießen, Germany \\ 2 GMuG mbH (Gesellschaft für Materialprüfung und Geophysik mbH), D-61231 Bad Nauheim, Germany; \\ k.plenkers@gmug.eu \\ * Correspondence: gerd.manthei@me.thm.de; Tel.: +49-152-0154-2896
}

Received: 31 July 2018; Accepted: 24 August 2018; Published: 9 September 2018

Featured Application: This article describes various applications of in situ acoustic emission (AE) monitoring in the context of structural health monitoring (SHM) in mines and extensively presents the state of the art in this field.

\begin{abstract}
A major task in mines and even more in underground repositories for nuclear waste is to investigate crack formation for evaluation of rock mass integrity of the host rock. Therefore, in situ acoustic emission (AE) monitoring are carried out in mines as part of geomechanical investigations regarding the stability of underground cavities and the integrity of the rock mass. In this work, the capability of in situ AE monitoring in the context of structural health monitoring (SHM) in mines and in various geological settings will be reported. SHM pointed out, that the AE network is able to monitoring AE activity in rock with a volume up to $10^{6}$ cubicmeter and distances up to $200 \mathrm{~m}$ (e.g., $100 \mathrm{~m} \times 100 \mathrm{~m} \times 100 \mathrm{~m}$ ) in the frequency range of $1 \mathrm{kHz}$ to $150 \mathrm{kHz}$. Very small AE events with source size in approximately centimeter to millimeter scale are detected. The results show that AE activity monitors rock deformation in geological boundaries due to convergence of the rock. In addition, high $\mathrm{AE}$ activity occurs in zones of dilatancy stress in homogenous rock. In conclusion in situ $\mathrm{AE}$ monitoring is a useful tool to observe instabilities in rock long before any damage becomes visible.
\end{abstract}

Keywords: in situ acoustic emission (AE) monitoring; structural health monitoring; mines; host rock

\section{Introduction}

For the safe use of various structures, a regular inspection is required. For critical infrastructures in particular, like aircraft, pressure vessels, and bridges as well as underground structures like mines, monitoring of their conditions is necessary. Therefore, methods for a reliable and automated monitoring are of great interest. Under these circumstances, structural health monitoring (SHM) has been an intriguing research topic in recent decades.

SHM is known as the continuous or periodical and automated method for monitoring and evaluating the condition of a monitoring subject. It is part of condition monitoring according to the International Organization for Standardization (ISO) 17359 [1]. This standard gives an overview of the basic procedures of condition monitoring and diagnostics programs for all types of machinery. The standard considers parameters such as vibration, temperature, flow rates, contamination, performance, and rotation speed, which are typically related to operation, state, and quality criteria. A concept is introduced of condition monitoring with the so-called root cause failure modes, which shows basic guidance on setting warning and alarm criteria, making diagnoses and predictions, and increasing their reliability. 
A traditional means of monitoring big structures is visual inspection by trained personnel. Although simple, visual inspection is not successful for realizing all sources of damage, so a need exists for more reliable methods. A wide range of methods is now available for SHM of large structures such as bridges. These methods can be broadly classified as local methods for machine condition monitoring and global methods for monitoring of the whole structure (see Table 1) [2]. Machine condition monitoring is not strictly concerned with structural health $(\mathrm{SH})$, but it requires information about the internal condition of the machine to be obtained externally. Vibration analysis is the most commonly applied method, and the analysis techniques have advanced greatly over the historic observation that if a machine is vibrating more than normal then it is likely to be faulty. These kinds of measurements are also used as predictive maintenance (PdM), which are performed to determine the condition of equipment in order to predict when maintenance should be done. One expects to save costs over routine or time-interval maintenance, because maintenance is carried out only when necessary or warranted. In order to identify wear particles or chemical contaminants, it is common to apply lubricant measurements, while the use of thermography to identify temperature anomalies is increasing.

Table 1. Type, aim, and characteristics of structural health monitoring (SHM) in machine condition, monitoring, and in monitoring of whole structures.

\begin{tabular}{|c|c|c|}
\hline Type of Measurements & Aim of Measurements & Characteristics \\
\hline \multicolumn{3}{|c|}{ SHM in machine condition monitoring } \\
\hline $\begin{array}{l}\text { Vibration measurements } \\
\text { Lubricant measurements } \\
\text { Thermography } \\
\text { Acoustic emission (AE) measurements }\end{array}$ & $\begin{array}{l}\text { Observation of machine vibration } \\
\text { Identification wear particles and } \\
\text { chemical contaminants } \\
\text { Identification of temperature anomalies } \\
\text { Identification of cracks }\end{array}$ & $\begin{array}{l}\text { - } \quad \text { infer the health of a whole machine } \\
\text { - } \quad \text { condition of rotating machines } \\
\text { - } \quad \text { mainly passive measurements } \\
\text { - } \quad \text { continuous and intermittent monitoring } \\
\text { - } \quad \text { small number of sensors are required } \\
\text { applied to e.g., large turbo machines, } \\
\text { bearing housing }\end{array}$ \\
\hline \multicolumn{3}{|c|}{ SHM in monitoring of entire structures } \\
\hline Vibration measurements & $\begin{array}{l}\text { Observation of vibration of a whole } \\
\text { structure }\end{array}$ & 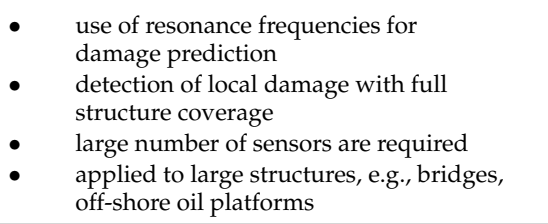 \\
\hline Fiber optics measurement & $\begin{array}{l}\text { Sensing mechanisms of optical fibers are } \\
\text { based on intensity, wavelength, and } \\
\text { interference of the light waves }\end{array}$ & $\begin{array}{l}\text { applied to a wide range of civil structures } \\
\text { such as building, bridges, pipelines, tunnels } \\
\text { and dams }\end{array}$ \\
\hline Load monitoring & Observation of strain, traffic or wind & applied to large structures such as bridges \\
\hline Ultrasonic measurements & $\begin{array}{l}\text { Observation of inhomogeneities in the } \\
\text { material induce changes to the } \\
\text { propagating waves }\end{array}$ & $\begin{array}{l}\text { transducers are used to introduce } \\
\text { high-frequency waves into a specimen and } \\
\text { receive the pulses } \\
\text { - } \quad \text { determination of position and size of flaw } \\
\text { - } \quad \text { very time consuming and expensive } \\
\text { - } \quad \text { aptive measurement } \\
\end{array}$ \\
\hline
\end{tabular}

For SHM of entire structures, several non-destructive evaluation/testing (NDE/NDT) techniques are available. These techniques do not involve the destruction of the structure during testing, as the name implies. Most commonly used non-destructive techniques are based on the use of elastic waves 
e.g., ultrasonic and acoustic emission (AE) measurements, and fiber optics measurements. Further details on these methods can be found in [3-5].

Vibration measurements usually give the global figure, indicating damage in the entire structure, and can also locate and assess the damage. The basis of the principle is that the changes in the global properties e.g., mass, stiffness, and damping of a structure cause a change in its modal properties such as natural frequencies and mode shapes. The modal properties such as modal flexibility and strain energy are used for the identification of damage [6-8]. These global methods usually use accelerometers to measure the vibration of the structure for calculating the modal properties. But the use of a vibration-based method in large structures such as bridges can be uncertain, just then, if damage may only cause negligible change in dynamic properties and thus may go unnoticed. Moreover, in order to find the exact location of damage, local methods are often better alternatives.

$\mathrm{AE}$ measurements are applied for machine condition monitoring as well as SHM of large structures. In engineering materials, some common sources of $\mathrm{AE}$ are initiation and growth of cracks, yielding, failure of bonds, fiber failure, and pullout in composites. It should be noted that only active or growing cracks emitted elastic waves. If cracks are present but do not grow, no AE is emitted. Ono $[9,10]$ gives in his papers a review on structural integrity evaluation and SH evaluation using AE.

Another application of SHM in the broadest sense is in situ AE monitoring in mines. This monitoring involves permanent $\mathrm{AE}$ measurements of microcracking in parts of the mine or the entire mine. A major task in underground storage like repositories for nuclear waste and deep mines is the safety assessment. Therefore, several geotechnical monitoring methods, for instance, micro-seismic measurements are used in many mines. This study demonstrates the capability of In situ AE monitoring for SHM in mines. Section 2 deals with fundamentals about in situ AE monitoring. After some comprehensive consideration of the scale between earthquakes and AE events, a list of various applications of in situ AE monitoring found in the literature (Section 2.2) is given. Sections $3-5$ show examples on in situ AE monitoring in salt mines, gold mines, and underground research laboratories.

\section{In Situ Acoustic Emission (AE) Monitoring-Fundamentals}

\subsection{Comprehensive Consideration of the Scale}

An interesting analogy can be made to AE events by comparing it to earthquakes, which can be regarded as largest natural occurring emission sources. The principal mechanism does not depend on the scale: The rapid release of elastic energy by processes of crack growth or deformation within the rock generates transient pulses of elastic wave energy as AE events. In an even larger scale, the same is true for earthquakes. Similar to AE sources, seismic waves propagate through the earth, and are detected with a global network of seismometers located around the world. Therefore, most of the theory of earthquakes can be transferred to AE sources [11,12]. Figure 1 shows the dependences between measured corner frequency $f_{C}$, the moment magnitude $M_{W}$, the seismic moment $M_{0}$, and the source radius $r_{0}$ for studies in earthquake seismology, microseismicity, in situ AE monitoring, and $\mathrm{AE}$ in laboratory (see more details in Box 1) [13]. In addition, in situ AE monitoring is reported from rock face monitoring e.g., on construction sites [14,15].

The largest and thereby the longest events, namely earthquakes, are found at the lowest end of the frequency scale (Figure 1). The focal length and displacement of an earthquake can amount to more than several hundred kilometers and up to several meters, respectively. Whereas global seismology exploits frequencies less than $1 \mathrm{~Hz}$, local seismology focuses on the analysis of frequencies of hundreds of Hertz or even $1000 \mathrm{~Hz}$. Recordings of microseismicity in dense local (e.g., borehole) networks or underground are limited to frequencies up to a few kilohertz. In these cases pendulum-based geophones or seismometers are utilized. The corner frequency in the field of microseismic measurements ranges between $5 \mathrm{~Hz}$ and some hundred Hertz with magnitudes from approximately 4.0 down to -2.0 . Above these frequencies, the range of in situ AE monitoring in rock begins with applications in mines. In the frequency rang of about $1 \mathrm{kHz}$ up to $200 \mathrm{kHz}$ accelerometers 
or special piezoelectric AE sensors were developed for in situ application in mines. Source-receiver distances realized depend strongly on rock type, but can reach up to $150 \mathrm{~m}$ in rocks with very low wave attenuation. The covered areas may have linear dimensions of up to $200 \mathrm{~m}$. The expected magnitudes are in the range between -2.0 and -5.0 .

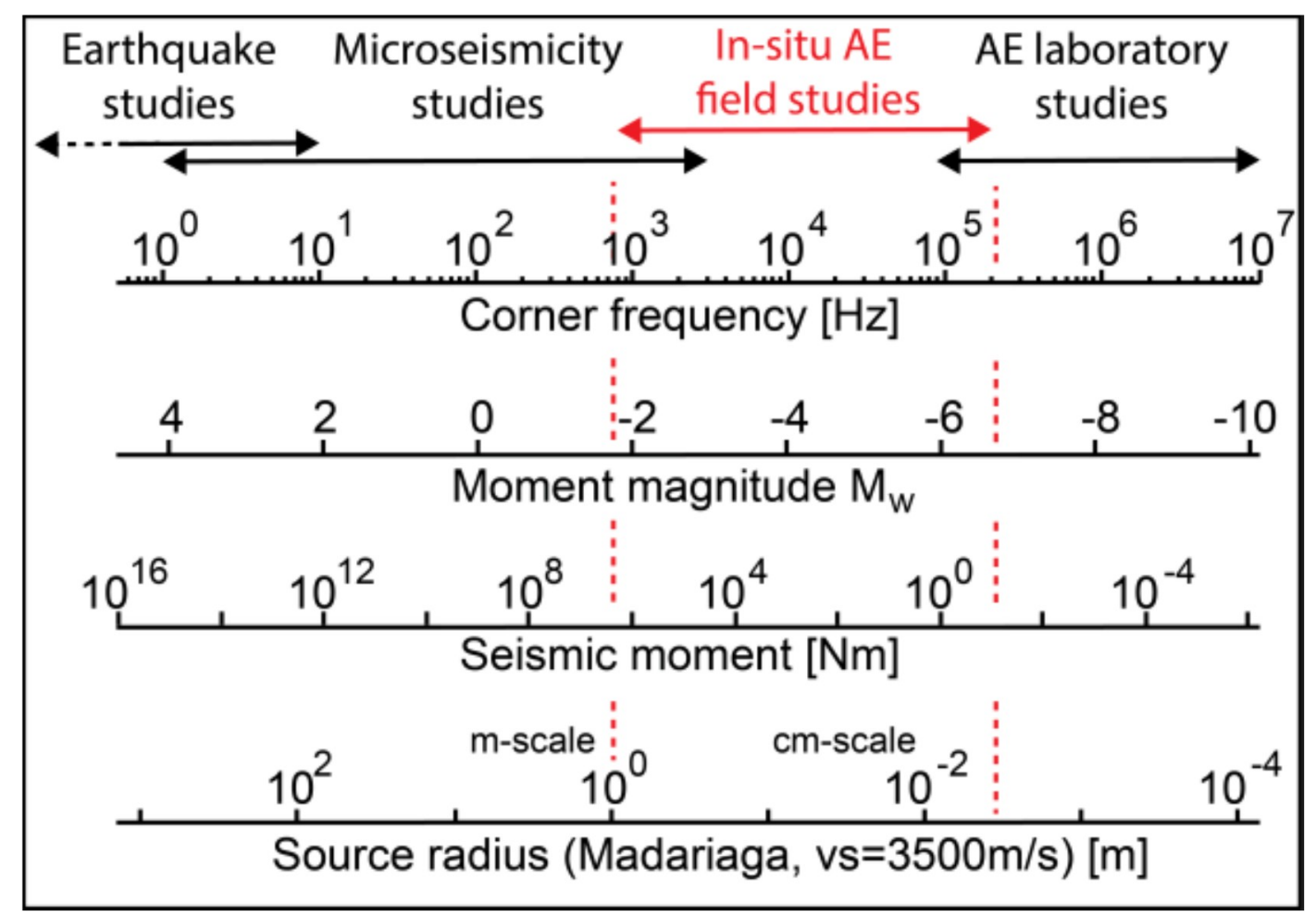

Figure 1. Relations between measured corner frequency $f_{C}$, moment magnitude $M_{W}$, seismic moment $M_{0}$, and the source radius $r_{0}$ for studies in earthquake seismology, microseismicity, In situ AE monitoring and AE in laboratory (see more details in Box 1) (modified from [13]).

On the other hand, the highest frequencies up to several $\mathrm{MHz}$ are utilized in laboratory studies. These frequencies are generated by $\mathrm{AE}$ events in the microscopic region, for instance by microcracking of rock or dislocation movement. Only sensitive piezoelectric sensors for laboratory applications are able to measure such high frequencies. In the laboratory, the source radius may extend to some micrometers only and the displacement (Burgers vector) is to be measured in nanometers. The expected magnitude of such small AE events is below -6.0 [11]. A detailed study on the theoretical limits on detection and analysis of small earthquakes in dependency on the sensitivity and frequency coverage of the monitoring network was published by Kwiatek and Ben Zion [16].

Figure 2 taken from Bohnhoff et al. [17] shows the co-seismic stress drop plotted with key earthquake source parameters over the entire bandwidth of observed rupture processes, extending from large natural earthquakes to AEs in the laboratory. The source parameters were calculated from individual data sets of natural earthquakes, induced seismicity in mines and reservoirs, and volcano seismicity [18-22]. AE data are unpublished results from the rock-deformation laboratory in the German research Centre for Geosciences, Potsdam, (GFZ)-Section 4.2. The Madariaga [23] circular source model is assumed to calculate source radii and the lines of constant static stress drop from $0.01 \mathrm{MPa}$ up to $100 \mathrm{MPa}$ and $v_{s}=3500 \mathrm{~m} / \mathrm{s}$ (see Box 1). 


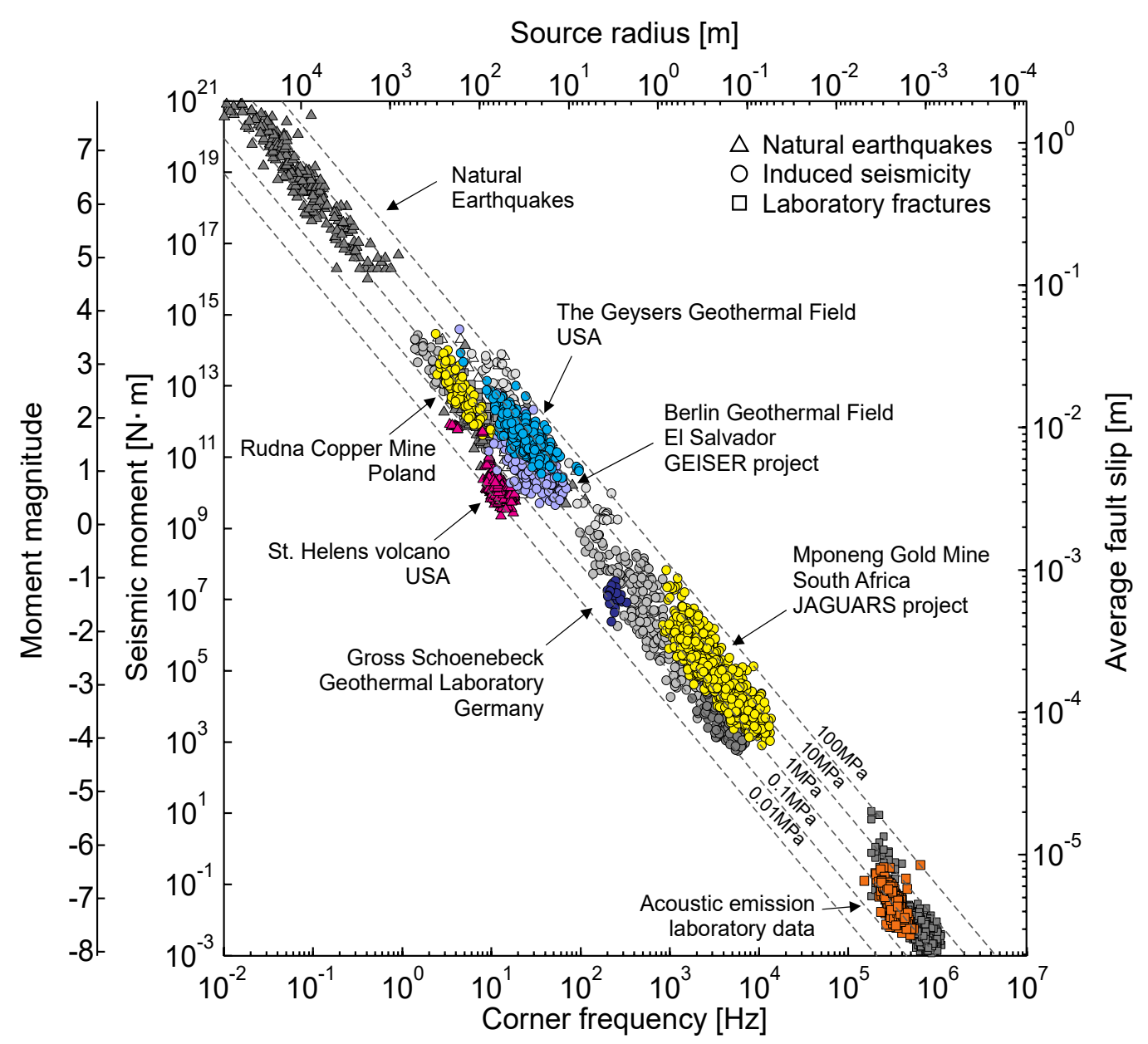

Figure 2. Dependence between seismic moment, moment magnitude, source radius, average fault slip, and corner frequency for natural earthquakes (gray rectangles) in comparison with data from other studies in the low-magnitude range. The Madariaga [18] circular source model is assumed to calculate source radii and the lines of constant static stress drop from $0.01 \mathrm{MPa}$ up to $100 \mathrm{MPa}$ and $v_{s}=3500 \mathrm{~m} / \mathrm{s}$ (see Box 1). This figure is an updated figure from Kwiatek et al. [16] and was first published in [17]. Reproduced with permission.

Box 1. Estimation of source radius, static stress drop, and moment magnitude.

Seismic moments $M_{0}$ and corner frequencies $f_{c}$ in Figure 2 were estimated from the spectral level of ground velocity or displacement spectra corrected for instrument response and wave propagation effects, as described in detail in the references. It follows that the dependency in Figure 2 between seismic moment and corner frequency are based on data-driven observables. The seismic moment is a measure of how much "work" an earthquake does in sliding when rock slips off other rock. It is necessary to take into account that the physical unit of $M_{0}$ is given in $\mathrm{N} \cdot \mathrm{m}$ (corresponds to $10^{7}$ dyne $\cdot \mathrm{cm}$ ).

The estimation of source radii, the lines of constant static stress drop, and the average fault slip are based on the model of Madariaga [23] and Brune [24]. Both modeled a circular fault and use the corner frequency $f_{c}$ to calculate the source radius $\mathrm{r}_{0}$ and the static stress drop $\Delta \sigma$. The stress drop and source radius is defined as $\Delta \sigma=7 / 16 \cdot M_{0} / r_{0}^{3}$ and $r_{0}=c \cdot v_{s} / 2 \pi f_{c}$, respectively $(c=2.34$ for Brune's model, $c=1.32$ for Madariaga's modell). The moment magnitude $M_{W}$ is calculated using the standard relation for tectonic events developed by Hanks et al. [25] $M_{W}=\left(\log _{10} M_{0}-9.1\right) / 1.5$. The formula is empirically established for tectonic earthquakes only. Extrapolation over so many orders of magnitude seems questionable, but is useful for visualization.

The question to which extent AE events represent double-couple shear events or events with a dominant isotropic component remains open. Owing to the AE sensor calibration problem (see Box 2), few studies exist that investigate reliably the source mode of AE events e.g., calculating the full moment tensor. Results from hydraulic fracturing studies suggest that AE events may represent sources with a major double-couple component $[26,27]$, whereas studies related to stress-induced AE events find indications for isotropic components or mixed mode events [28-31]. 


\subsection{Applications and Characteristics of In Situ AE Monitoring}

Many examples of application of in situ AE monitoring in mines as found in the literature are given in Table 2. This table shows the test site of the project, the resulting publications, the type of AE networks with source-receiver distance and mode of recording, and the rock type with number of recorded events. Above the frequencies of microseismic measurements, the lower frequency of the in situ AE method begins at $1 \mathrm{kHz}$ and ranges up to approximately $200 \mathrm{kHz}$. Due to the high sensitivity of the AE sensors, the in situ AE method allows to monitor fractures in the millimeter scale to decimeter scale (see Figure 2). This is important information because such small events indicate weakening in the rock long before macroscopic fractures occur [32-34]. Due to the high frequencies, the signals of $\mathrm{AE}$ events attenuate more than signals of microseismic events [35,36]. Thus, in situ AE monitoring is limited to a few tens of meters in hard rock or a few meters only in soft rock like clay rock or sedimentary rock. However, if the rock is very homogeneous and the attenuation of the seismic waves is low, larger rock volumes over $150 \mathrm{~m}$ in length can be monitored [12,33-38]. The applications in Table 2 can be roughly divided into three groups. The first group shows applications from underground laboratories in Switzerland and Sweden. The second group deals with the application of in situ AE monitoring in gold mines in South Africa. The third and biggest group shows applications in salt mines in Germany. These in situ measurements in rock salt often focused on monitoring AE activity caused by work like backfilling [39,40], excavation [41] or gas and fluid injection [42]. Early projects in in situ AE monitoring were limited to small rock volumes.

\subsection{Method of In Situ AE Monitoring}

With the in situ AE method, a network of AE sensors records very small events with low seismic energy in the kilohertz range. The frequency range of in situ AE monitoring is 1 to approximately $200 \mathrm{kHz}$. In contrast to seismic and micro-seismic sensors, AE sensors do not measure ground movement based on the principle of spring-mass or a pendulum, but detect stress changes purely based on the piezoelectric effect. AE sensors are accordingly piezoelectric-based sensors, which are much more sensitive in the $\mathrm{kHz}$ frequency range than spring-mass based accelerometers or pendulum-based geophones/seismometers as shown in Plenkers et al. [36] and Zang et al. [43]. But, in situ AE measurements are often missing absolute calibration of the AE sensors (see Box 2). The differences between those sensor types are discussed in more detail in Box 3 .

Box 2. Annotations about characterization of AE sensors.

\footnotetext{
An important issue in today's works on in situ AE measurements is the often missing absolute calibration of the AE sensors. These piezoelectric sensors (not to be confused with piezoelectric accelerometers, see Box 3) work mostly in resonant mode and do not have a flat sensor response. For this reason, the AE sensors are very sensitive at the resonant frequencies, but the exact sensor response necessary for magnitude estimations (especially based on waveform amplitudes) or source type analysis is normally unknown. By contrast, AE sensors used at frequencies $f$ much higher than $100 \mathrm{kHz}$ and used in the laboratory are successfully calibrated [44-51]. The calibration of AE sensors used in situ remains difficult due to the longer wavelength [45]. In addition, in situ coupling of AE sensors can have a severe influence on the sensor recording and need to be taken into account. Today, mostly two characterization methods are used in situ. sensor characterization by signal deconvolution $[16,52,53]$ or by regression analysis $[27,54,55]$. An absolute calibration technique for reliable in situ calibration is still missing.

For this reason, in the case of in situ AE measurements in rock, magnitudes are often listed nominal magnitudes [56] or relative magnitudes [54]. These magnitudes are useful to gain insights into the relative event size, but may not be compared directly to other seismic magnitudes or in between events from different regions, different source types or different source-receiver distances as the effect of the sensors resonant response is not corrected for. Few studies exist of in situ AE events, where reliable source parameters (seismic moments) were estimated after careful sensor characterization and correction for the sensor response in situ $[16,27,53,55]$.
} 
Many authors applied the in situ AE method in order to detect AE events in mines. This method was applied to most applications as shown in Table 2. Due to the high measurement frequencies and the very high number of $\mathrm{AE}$ events, fast data acquisition systems are required. A multi-channel transient recorder (often 16 or 32 channels) running in trigger mode does the digitization. This means, a limited time window (e.g., $32 \mathrm{~ms}$ ) is stored, when the threshold was passed. In this time window, all signals modes like $\mathrm{P}$ wave and $\mathrm{S}$ wave should be included. In order to detect the complete waveforms during the whole measurements, some measuring system also allows continuous recording of the measuring signals, where the waveform is recorded without interruption.

Box 3. Comparison of accelerometer and piezoelectric AE sensor.

A combination of AE sensors and triaxial accelerometers were used in the gold mines in South Africa, salt mines in Germany, and underground hard rock laboratories in Switzerland and Sweden. These AE sensors manufactured by Gesellschaft für Materialprüfung und Geophysik (GMuG) uses a piezoelectric disk of PZT ceramic, which is sensitive in the frequency range from approximately $1 \mathrm{kHz}$ to approximately $200 \mathrm{kHz}$. On the other hand, the commercial triaxial piezoelectric accelerometer composed of Wilcoxon 736T has a flat frequency response between $100 \mathrm{~Hz}$ and $25 \mathrm{kHz}$ with a sensitivity of $100 \mathrm{mV} / \mathrm{g}$ and a resonance frequency at $60 \mathrm{kHz}$. Zang et al. [43] concluded, "that the Wilcoxon accelerometers were not able to record AE events detected with the in situ AE sensors, despite the fact that AE events were present in the frequency range of the accelerometer". Note that the in piezoelectric accelerometers the piezoelectric disk is solely used to measure the movement of the seismic mass, whereas for AE sensors the piezoelectric effect is exploited to measure stress changes.

$\mathrm{AE}$ sensors are piezoelectric sensors that are much more sensitive in the kilohertz frequency range than a spring-mass based accelerometer. In the case of a constant acceleration, the acceleration force is in equilibrium with the restoring force of the spring deflected by $x$ with the spring constant $c . F=m \cdot a=c \cdot x$. The measuring sensitivity $S$ of the system results in $S=x / a=m / c$, if $x$ is proportional to the output voltage. Accordingly, a large mass and a low spring stiffness lead to a high measuring sensitivity. In the dynamic case, damping forces and inertial forces have to be taken into account in addition to the spring force. The essential damping force is proportional to the velocity $\dot{x}$ and is described with the attenuation coefficient $p$. The inertial force is proportional to the acceleration. The resulting equation describes a resonant system: $F=m \cdot a=c \cdot x+p \cdot \dot{x}+c \cdot \ddot{x}$. Starting from a negligible damping $(p \approx 0)$, it has a resonance frequency $\omega_{0}=\sqrt{c / m}$. Thus, according to the above equation, the measurement sensitivity $S$ is firmly linked to the resonance frequency $\omega_{0}$ in the following way: $\omega_{0}^{2} \cdot S=1$. This means that a twice as high resonance frequency must be paid for with sensitivity reduced to the factor $1 / 4$. Such spring-mass systems show only sufficiently below their resonance frequency a sufficiently constant proportionality between the measured variable and the deflection. 
Table 2. Characteristics and applications of in situ AE monitoring in mines

\begin{tabular}{|c|c|c|c|c|}
\hline Test Site/Project & Keyword & Publications, Year & $\begin{array}{c}\text { Network/Source-Receiver } \\
\text { Distance R/Mode of Recording }\end{array}$ & Rock Type/No. of AE Events \\
\hline Underground tunnel, Japan & Hydraulic fracturing & $\begin{array}{l}\text { Sasaki et al. [57], } 1987 \\
\text { Ohtsu [58], } 1991\end{array}$ & $\begin{array}{l}17 \mathrm{AE} \text { sensors (up to } 100 \mathrm{kHz} \text { ), } \\
17 \text { accelerometers, } \mathrm{R} \approx 1 \mathrm{~m}, \\
\text { trigger mode with waveforms }\end{array}$ & $\begin{array}{l}\text { Siliceous sandstone } \\
200 \text { AEs during four hydraulic fracturing tests } \\
\text { (including microseismic events) }\end{array}$ \\
\hline $\begin{array}{l}\text { Underground research laboratory (URL), } \\
\text { Canada, TSX Project }\end{array}$ & Excavation/tunnel sealing & $\begin{array}{l}\text { Young \& Collins [59], } 1999 \\
\text { Young et al. [60], 2000 } \\
\text { Young \& Collins [61], } 2001 \\
\text { Collins \& Pettitt [62], } 2002 \\
\text { Young \& Collins [63], } 2004\end{array}$ & $\begin{array}{l}16 \mathrm{AE} \text { sensors }(40 \text { to } 400 \mathrm{kHz}), \\
16 \text { accelerometers, } \mathrm{R} \approx 10 \mathrm{~m} \\
\text { trigger mode with waveforms }\end{array}$ & $\begin{array}{l}\text { Granite } \\
15,350 \text { AEs in } 5 \text { months } \\
\text { approximately } 400 \mathrm{~m} \text { depth }\end{array}$ \\
\hline Salt mine Asse, Germany & Cavity stability/heating & $\begin{array}{l}\text { Eisenblätter et al. [41], } 1998 \\
\text { Dahm \& Manthei, [64], } 1998\end{array}$ & $\begin{array}{l}29 \mathrm{AE} \text { sensors }(100 \mathrm{kHz}), \\
\mathrm{R} \approx 100 \mathrm{~m} \text {, trigger mode with waveforms }\end{array}$ & $\begin{array}{l}\text { Salt rock, } \\
250,000 \text { AEs in } 11 \text { months }\end{array}$ \\
\hline \multirow[t]{2}{*}{ Salt mine Bernburg, Germany } & Hydraulic fracturing & $\begin{array}{l}\text { Manthei et al. [65], } 1998 \\
\text { Dahm et al. [66], } 1999\end{array}$ & $\begin{array}{l}8 \mathrm{AE} \text { sensors (up to } 250 \mathrm{kHz} \text { ) } \\
\mathrm{R} \approx 10 \mathrm{~m}\end{array}$ & $\begin{array}{l}\text { Salt rock } \\
1500 \text { AEs during eleven hydraulic fracturing } \\
\text { tests }\end{array}$ \\
\hline & & $\begin{array}{l}\text { Manthei et al. [26], } 2001 \\
\text { Manthei et al. [67], } 2003\end{array}$ & $\begin{array}{l}\text { trigger mode with waveforms } \\
8 \mathrm{AE} \text { sensors (up to } 250 \mathrm{kHz} \text { ) and } \\
\text { hydraulic fracturing tool, } \mathrm{R} \approx 5 \mathrm{~m} \\
\text { trigger mode with waveforms }\end{array}$ & $\begin{array}{l}\text { Salt rock } \\
15,000 \text { AEs during four hydraulic fracturing } \\
\text { tests }\end{array}$ \\
\hline $\begin{array}{l}\text { Äspö Hard Rock Laboratory (HRL), } \\
\text { Sweden }\end{array}$ & Excavation & Pettitt et al. [68], 2002 & $\begin{array}{l}24 \mathrm{AE} \mathrm{sensors} \mathrm{(35} \mathrm{to} 350 \mathrm{kHz} \text { ) } \\
\mathrm{R} \approx 10 \mathrm{~m} \text {, trigger mode with waveforms }\end{array}$ & $\begin{array}{l}\text { Dioritic granite } \\
884 \mathrm{AEs} \text { in } 24 \text { hours }\end{array}$ \\
\hline $\begin{array}{l}\text { Salt mine Morsleben, Germany } \\
\text { (southern part) }\end{array}$ & - & $\begin{array}{l}\text { Spies et al. [69], 2004 } \\
\text { Manthei et al. [28], } 2007\end{array}$ & $\begin{array}{l}24 \mathrm{AE} \text { sensors (up to } 100 \mathrm{kHz} \text { ) } \\
\mathrm{R} \approx 100 \mathrm{~m} \text {, trigger mode }\end{array}$ & $\begin{array}{l}\text { Salt rock } \\
50,000 \text { AEs in one month } \\
\text { approximately } 400 \mathrm{~m} \text { depth }\end{array}$ \\
\hline $\begin{array}{l}\text { Salt mine Morsleben, Germany } \\
\text { (central part) }\end{array}$ & $\begin{array}{l}\text { Backfilling } \\
\text { Cavity stability }\end{array}$ & $\begin{array}{l}\text { Spies \& Eisenblätter [37], } 2001 \\
\text { Manthei et al. [70], 2001 } \\
\text { Spies et al. [39], 2005 } \\
\text { Manthei et al. [35], 2006 } \\
\text { Köhler et al. [71], 2009 } \\
\text { Becker et al. [40], } 2010 \\
\text { Becker et al. [72], } 2014\end{array}$ & $\begin{array}{l}48 \mathrm{AE} \text { sensors (up to } 100 \mathrm{kHz} \text { ) } \\
\mathrm{R} \approx 200 \mathrm{~m} \text {, trigger mode }\end{array}$ & $\begin{array}{l}\text { Salt rock } \\
100,000 \text { AEs in one month } \\
\text { approximately } 400 \mathrm{~m} \text { depth }\end{array}$ \\
\hline $\begin{array}{l}\text { Mponeng gold mine, Carletonville, } \\
\text { South Africa } \\
\text { JAGUARS project }\end{array}$ & Pillar stress loading & $\begin{array}{l}\text { Nakatani et al. [77], } 2008 \\
\text { Yabe et al. [33]], 2009 } \\
\text { Plenkers et al. [36], } 2010 \\
\text { Kwiatek et al. [55], } 2010 \\
\text { Plenkers et al. [52], } 2011 \\
\text { Kwiatek et al. [16], } 2011 \\
\text { Naoi et al. [74], 2011 } \\
\text { Davidsen et al. [75], } 2013 \\
\text { Kwiatek \& BenZion [30], } 2013 \\
\text { Davidsen et al. [76], 2012 } \\
\text { Ziegler et al. [777, 2015 } \\
\text { Yabe et al. [78], 2015 } \\
\text { Kozlowska et al. [79], } 2015\end{array}$ & $\begin{array}{l}8 \mathrm{AE} \text { sensors }(1 \text { to } 200 \mathrm{kHz}) \text { and } \\
1 \text { triaxial accelerometer, } \\
\mathrm{R} \approx 10 \mathrm{~m} \text { to } 200 \mathrm{~m} \text {, trigger mode with } \\
\text { waveforms }\end{array}$ & $\begin{array}{l}\text { Quarzite/Gabbro } \\
\text { more than } 500,000 \mathrm{AEs} \text { in } 2 \text { years } \\
\text { approximately } 3200 \mathrm{~m} \text { depth }\end{array}$ \\
\hline
\end{tabular}


Table 2. Cont.

\begin{tabular}{|c|c|c|c|c|}
\hline Test Site/Project & Keyword & Publications, Year & $\begin{array}{c}\text { Network/Source-Receiver } \\
\text { Distance R/Mode of Recording }\end{array}$ & Rock Type/No. of AE Events \\
\hline Salt mine Merkers, Germany & Gas loading & $\begin{array}{l}\text { Doerner et al. [80], } 2012 \\
\text { Manthei et al. [42], } 2012 \\
\text { Popp et al. [81], 2015 } \\
\text { Plenkers et al. [82], } 2018\end{array}$ & $\begin{array}{l}8 \mathrm{AE} \text { sensors }(1 \text { to } 150 \mathrm{kHz} \text { ) and } \\
4 \mathrm{AE} \text { sensors }(1 \text { to } 80 \mathrm{kHz}) \\
\mathrm{R} \approx 10 \mathrm{~m} \text { to } 60 \mathrm{~m} \text {, trigger mode with } \\
\text { waveforms }\end{array}$ & $\begin{array}{l}\text { Salt rock } \\
\text { more than 5,000,000 AEs in } 2 \text { years } \\
\text { approximately } 300 \mathrm{~m} \text { depth }\end{array}$ \\
\hline $\begin{array}{l}\text { Mont Terri URL, St Ursanne, } \\
\text { Switzerland }\end{array}$ & Excavation & Le Gonidec et al. [83], 2012 & $\begin{array}{l}16 \mathrm{AE} \text { sensors (unknown) and } \\
4 \mathrm{AE} \text { sensors ( } 2 \mathrm{kHz} \text { to } 60 \mathrm{kHz}) \\
\mathrm{R} \approx 0.3 \mathrm{~m} \text { to } 6.5 \mathrm{~m} \text {, trigger mode with } \\
\text { waveforms }\end{array}$ & $\begin{array}{l}\text { Opalinus clay } \\
\text { more than } 20,000 \text { AEs in } 2 \text { weeks ( } 2127 \text { located), } \\
300 \text { m depth }\end{array}$ \\
\hline $\begin{array}{l}\text { Cooke } 4 \text { gold mine, South Africa, } \\
\text { SATREPS project }\end{array}$ & Mining stress & $\begin{array}{l}\text { Naoi et al. [53], } 2013 \\
\text { Naoi et al. [84], } 2015 \\
\text { Naoi et al. [85], } 2015 \\
\text { Naoi et al. [86], 2015 } \\
\text { Moriya et al. [34], } 2015\end{array}$ & $\begin{array}{l}24 \mathrm{AE} \text { sensors }(1 \text { to } 50 \mathrm{kHz}) \text { and } \\
6 \text { triaxial accelerometers ( } 50 \mathrm{~Hz} \text { to } 10 \text { or } 25 \mathrm{kHz} \text { ), } \\
\mathrm{R} \approx 0 \mathrm{~m} \mathrm{to} 180 \mathrm{~m} \text {, trigger mode with } \\
\text { waveforms }\end{array}$ & $\begin{array}{l}\text { Quartzite } \\
365,237 \text { AEs in approximately } 3 \text { months } \\
1000 \text { m depth }\end{array}$ \\
\hline Salt mine Asse, Germany & Cavity stability & Philipp et al. [38], 2015 & $\begin{array}{l}16 \mathrm{AE} \text { sensors }(1 \text { to } 100 \mathrm{kHz}) \\
\mathrm{R} \approx 0 \mathrm{~m} \text { to } 180 \mathrm{~m} \text {, trigger mode with } \\
\text { waveforms }\end{array}$ & $\begin{array}{l}\text { Salt rock } \\
\text { more than 100,000 AEs in } 10 \text { month, } \\
300 \text { m depth }\end{array}$ \\
\hline $\begin{array}{l}\text { Äspö Hard Rock Laboratory (HRL), } \\
\text { Sweden }\end{array}$ & Hydraulic fracturing & $\begin{array}{l}\text { Zang et al. [43], } 2017 \\
\text { López et al. [87], } 2017 \\
\text { Kwiatek et al. [27], } 2018\end{array}$ & $\begin{array}{l}11 \mathrm{AE} \text { sensors }(1 \text { to } 100 \mathrm{kHz} \text { ) and } 4 \\
\text { accelerometers ( } 50 \mathrm{~Hz} \text { to } 25 \mathrm{kHz}), \mathrm{R} \approx 10 \mathrm{~m} \text { to } \\
30 \mathrm{~m} \text {, trigger mode with waveforms and } \\
\text { continuous recording }\end{array}$ & $\begin{array}{l}\text { Granodiorite/Diorite-gabbro/Granite } \\
196 \text { located AE events during six hydraulic } \\
\text { fracturing tests, (more than } 4000 \text { AEs during } \\
\text { one hydraulic fracturing fracturing test in } \\
\text { continuous data) } \\
400 \mathrm{~m} \text { depth }\end{array}$ \\
\hline Grimsel Test Site (GTS), Switzerland & Hydraulic fracturing & $\begin{array}{l}\text { Gischig et al. [54], } 2018 \\
\text { Jalali et al. [88], } 2018\end{array}$ & $\begin{array}{l}28 \mathrm{AE} \text { sensors ( } 1 \text { to } 100 \mathrm{kHz} \text { ) and } 4 \\
\text { accelerometers ( } 50 \mathrm{~Hz} \text { to } 25 \mathrm{kHz}), \mathrm{R} \approx 9 \mathrm{~m} \text { to } 30 \\
\mathrm{~m} \text {, trigger mode with waveforms and } \\
\text { continuous recording }\end{array}$ & $\begin{array}{l}\text { Granodiorite, } \\
\text { 2,000 AEs during three hydraulic fracturing } \\
\text { tests } \\
400 \mathrm{~m} \text { to } 500 \mathrm{~m} \text { depth }\end{array}$ \\
\hline Salt mine Merkers, Germany & Brine loading & Plenkers et. al. [82], 2018 & $\begin{array}{l}8 \mathrm{AE} \text { sensors }(1 \text { to } 100 \mathrm{kHz} \text { ) and } 4 \mathrm{AE} \text { sensors }(1 \\
\text { to } 150 \mathrm{kHz} \text { ) and } 4 \mathrm{AE} \text { sensors ( } 1 \text { to } 80 \mathrm{kHz} \text { ), } \\
\mathrm{R} \approx 5 \mathrm{~m} \text { to } 30 \mathrm{~m} \text {, trigger mode with waveforms } \\
\text { and continuous recording }\end{array}$ & $\begin{array}{l}\text { Salt rock } \\
\text { approximately } 300 \mathrm{~m} \text { depth }\end{array}$ \\
\hline
\end{tabular}


Often real-time processing (P- and S-wave onset picking and localization) of events is implemented in trigger mode recording. As data needs to be processed and stored on computer hard drives some dead time in recording occurs in between different windows. In the trigger mode approximately $10 \mathrm{AE}$ events per second can be recorded. The signals of AE events are recorded when a specified threshold is crossed on one or more channels. As mentioned above, continuous recording of the waveform is possible in the last few years, as large computer storage is now available. Typical sampling rates are $500 \mathrm{kHz}$ to $1 \mathrm{MHz}$. The P-wave and S-wave onsets are automatically picked after band-pass filtering of the traces by applying an adapted, speed-optimized short-term-average to long-term-average (STA-to-LTA) trigger algorithm [89]. After picking of the onsets, a least-square algorithm based on a gradient method is used to determine the location of the AE events. A location is valid if a sufficient number of P-wave and S-wave onsets are used for source location and the time residuals are small enough. With this location procedure working, noise without discernible onsets can be eliminated. For post-analysis, the digitized waveforms and location results are stored on hard disk. With fast Internet access, the AE measuring system can be remotely controlled. Transient noise of anthropogenic or electronic origin on the other hand is often localized and can pollute the seismic catalog, especially in active mines $[36,38,87]$.

\section{In Situ AE Monitoring in Salt Mines}

\subsection{Salt Mine Asse in Germany}

The first example we present in this review is the study of Philipp et al. [38], which demonstrates structural monitoring in cavity roofs of the salt mine Asse II. In the Asse II mine in Lower Saxony there is the risk of permanent brine inflows due to failure processes in pillars and tunnels in the southern flank and in the adjacent overburden [90,91]. In order to monitor these failure processes, in situ AE measurements are carried out to detect microcracking in the roof of two cavities (that are subject to work operations and noise). It is expected, that $\mathrm{AE}$ events outline weakening in rock, structural damage due to dilatation and other dynamic processes long before significant damage is visible and in areas that are not accessible.

Figure 3a displays a top view onto the two chambers, which are monitored. The contours of the chambers are indicated by rectangles. North is on top. The monitoring system consists of two networks with 16 AE sensors, which are installed in short borehole of $1 \mathrm{~m}$ to $3 \mathrm{~m}$ length in the chamber's roof. The positions of the AE sensors of the western and eastern galleries are marked by grey and black dots, respectively. The dashed lines in Figure 3a indicate the positions of Crosscut 1 to 4 with a width of $12 \mathrm{~m}$. Figure $3 \mathrm{~b}$ shows a perspective view of the two test sites. The vertical short lines mark the boreholes for the bottom-view AE sensors, which are especially sensitive in the frequency range $1 \mathrm{kHz}$ to $150 \mathrm{kHz}$.

Data is recorded in trigger-mode ( $1 \mathrm{MHz}$ sampling rate) and automatically processed i.e., that events recorded are localized in near-real time. For this P- and S-wave onset picking is performed using a picking algorithm based on the Hilbert transform. The network geometry of both networks (network dimension $37 \mathrm{~m} \times 31 \mathrm{~m} \times 5 \mathrm{~m}$ and $46 \mathrm{~m} \times 39 \mathrm{~m} \times 4.5 \mathrm{~m}$ ) differs owing to the actual usage of the two chambers that define the accessibility of the roof for sensor installation e.g., the roof could not be accessed above three large brine ponds. The monitoring project has been ongoing for several years, but the study considers data of a 10-month period, namely the time period 4 February to 31 November 2013. In this time period more than $100,000 \mathrm{AE}$ events were recorded that populate a rock volume of approximately $250 \mathrm{~m} \times 250 \mathrm{~m} \times 160 \mathrm{~m}$ outlining dynamic processes not only in the chambers roof, but also in the salt dome flank and in the upper salt dome.

Figure 4 displays a geological cross section (sketch) through the Asse salt dome. The sketch shows that the southern flank (left-hand side) has a steep slip. 

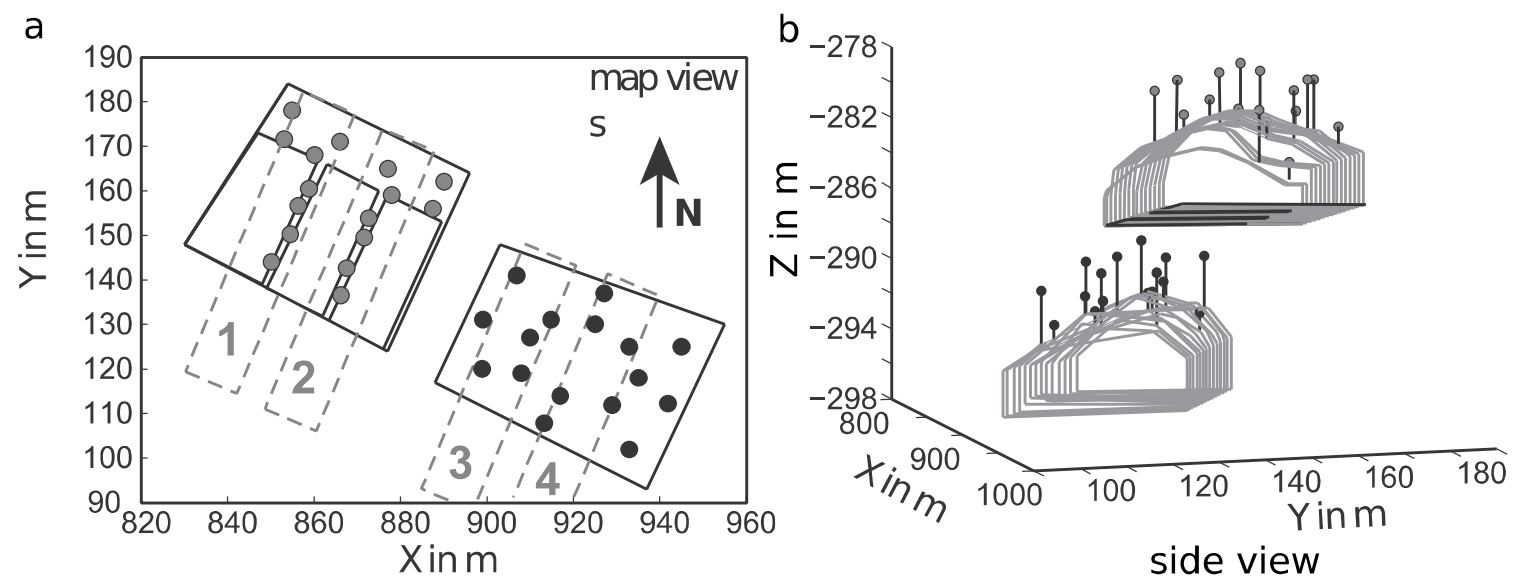

Figure 3. (a). Top view onto the monitored chambers. The contours of the chambers are indicated by squares. North is on top. The positions of the AE sensors are marked by grey and black dots. (b) Perspective view of the two test sites. The vertical short lines mark the boreholes for the bottom-view AE sensors (modified from [38]).

In this cross section, the chambers in Figure 3 are marked by a rectangle at the left-hand side in Figure 4 . This figure gives a good overview of the approximate location of the four main clusters $\mathrm{C} 1$, $\mathrm{C} 2, \mathrm{C} 3 \mathrm{a}$, and $\mathrm{C} 3 \mathrm{~b}$ of AE events, which are marked by framed zones. More than $70 \%$ of the located AE events occur in the Cluster $\mathrm{C} 1$ along the so-called southern flank of the salt mine Asse.

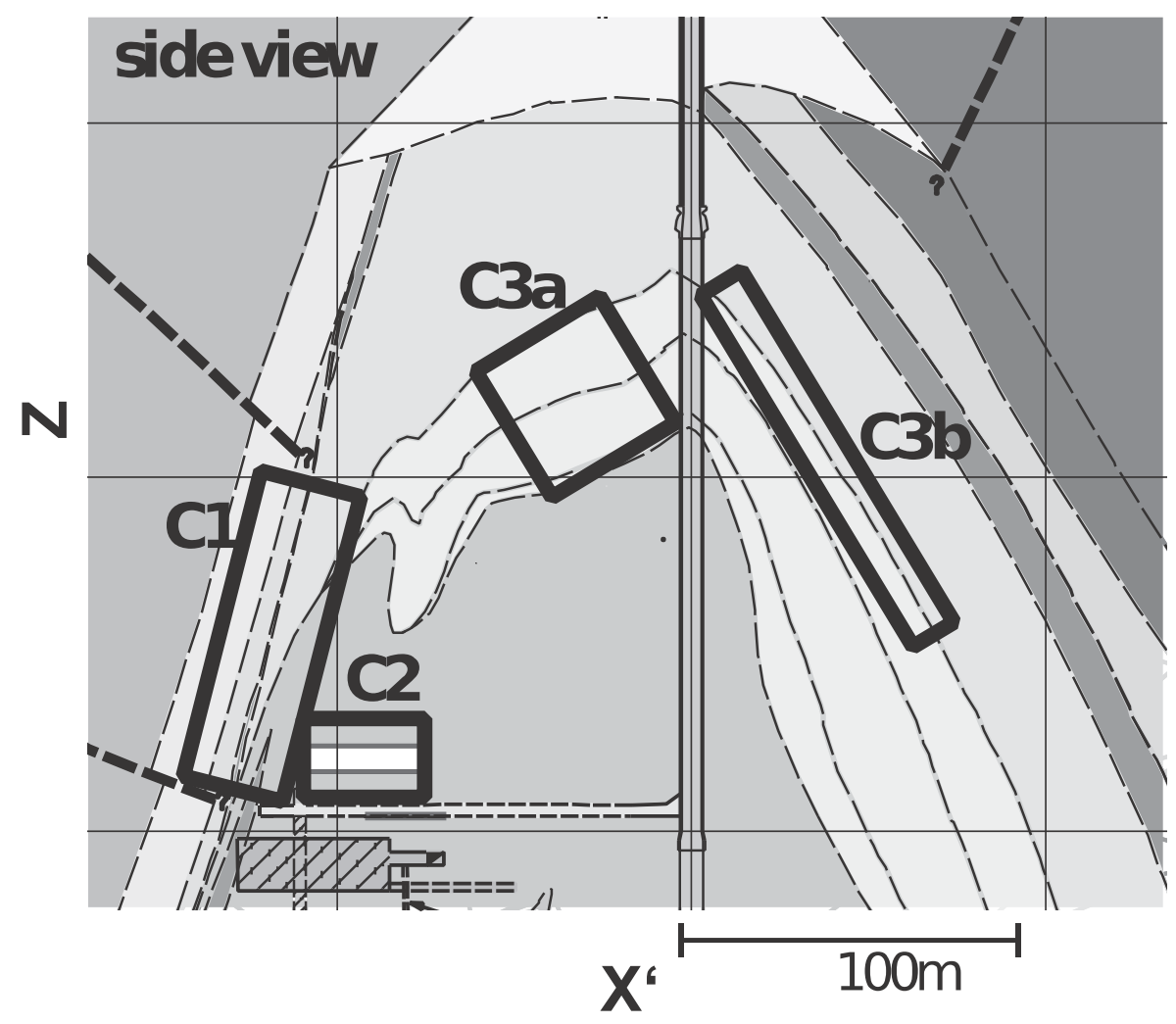

Figure 4. Geologic cross section (sketch) of the Asse salt mine with the four AE clusters C1, C2, C3a, and C3b (framed zones) [38].

In addition to these events, high $\mathrm{AE}$ activity occurs in zones above the roof of the chambers. At the roof of the western and eastern chamber (Cluster C2) more than 5000 and 10,000 AE events are located, respectively. In addition, in the upper part of the salt dome and the northern flank (Clusters $3 a$ 
and $3 b$ ) two clusters of AE events are located. Because of the low wave attenuation of salt rock, the AE networks are very sensitive, so that source-receiver distances greater than $150 \mathrm{~m}$ are possible. Figure 5 displays AE activity above the roof of the chambers and in the southern flank above the two chambers in a rotated coordinate system. The location of the AE events are marked as black dots in the four crosscuts as shown in Figure 3. In Crosscut 1 and 2 (left-hand side) and Crosscut 3 and 4 (right-hand side), the AE events were recorded by the AE system in the western and eastern chamber, respectively. The width of the crosscut is about $12 \mathrm{~m}$.
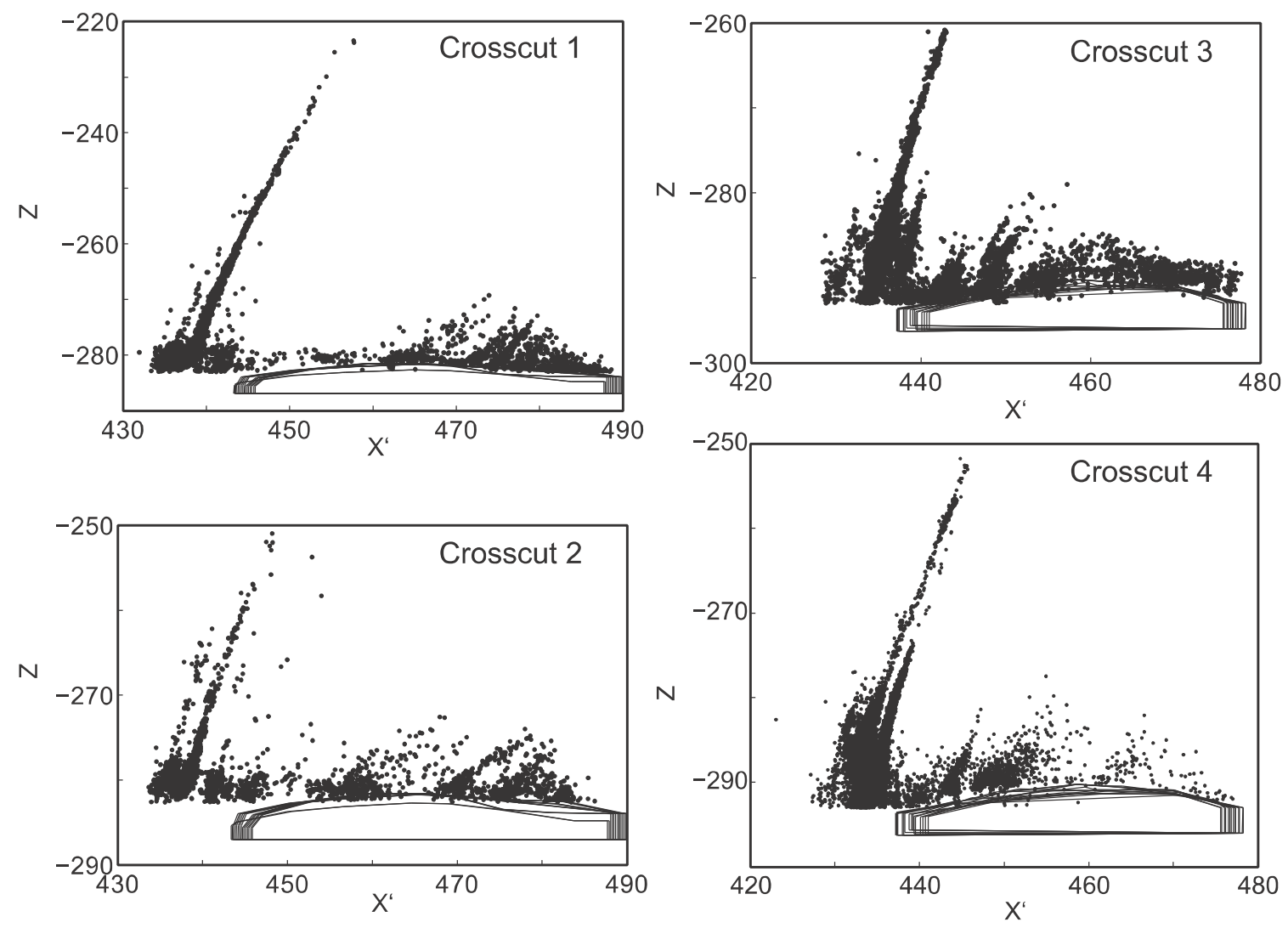

Figure 5. Location of $\mathrm{AE}$ events (black dots) in projection onto four vertical crosscuts in a rotated coordinate system above the chamber and along the anhydrite-host rock boundary at the southern flank [38]. All dimensions are given in meter.

The observed AE activity is not homogenously distributed but clusters clearly, in this way outlining planes of activity. In the chamber's roof most events outline planes oriented east-west and dipping to the south according to the salt's layering. The events extend up to $15 \mathrm{~m}$ from the roof into the salt rock, but at greater depth no activity is recorded, which demonstrates that currently no active damage process is occurring. In the roof of the chambers, all events occur in a homogenous part of the younger salt rock (Leine formation) and most likely correspond to damage processes owing to stress re-distribution. A geomechanical survey confirmed an increased permeability in the area of AE clusters, but did not show macroscopic damage.

The strongest AE activity is observed on the southern flank of the salt dome. The events outline a plane of activity that is oriented roughly east-west and dipping to the south. The AE events seem to follow the rock salt-anhydrite-sandstone rock boundary, which is subject to significant geomechanical processes including the loss of integrity owing to a barrier thickness of only $15 \mathrm{~m}$ in the upper mine. Events are observed as far as $70 \mathrm{~m}$ above the network. Within this plane, AE events cluster on vertical structures. 
Overall, the authors conclude that although a singular AE event is too small to have a damage potential, the $\mathrm{AE}$ events are clearly able to outline in high-resolution areas and, even more precisely, the exact position, extension, and orientation of potential damage zones.

\subsection{Salt Mine Merkers in Germany}

From another salt mine in Germany, SHM during a borehole loading experiment is reported by Manthei et al. [42], Popp et al. [81], and Plenkers et al. [82]. In the first experiment that took place from January 2010 to January 2012, the rock response of four different stages were monitored using in situ AE monitoring: (1) pre-excavation; (2) drilling of wide-diameter (1.3 m diameter, $60 \mathrm{~m}$ extension) borehole; (3) partial backfill with $\mathrm{MgO}$ concrete to create gas tight seal; and (4) during borehole loading with compressed air. In the second experiment, that took place October 2017 to Summer 2018, in the same wide-diameter borehole, the rock response to brine loading was monitored [82].

The monitoring system of the first experiment consisted of $12 \mathrm{AE}$ sensors installed in four monitoring boreholes in $12 \mathrm{~m}$ to $15 \mathrm{~m}$ distance to the large injection borehole. The sensors were equally spaced along the borehole and therefore, monitor the whole borehole with a similar recording sensitivity. The $\mathrm{AE}$ events are recorded in trigger mode. The dimension of the network is $28 \mathrm{~m} \times 25 \mathrm{~m} \times 27 \mathrm{~m}$ monitoring a rock volume of approximately $40 \mathrm{~m} \times 40 \mathrm{~m} \times 90 \mathrm{~m}$.

Figure 6 shows at the left-hand side and in the middle results of the located AE events during excavation and cementation in side view (projection onto the $x-z$ plane). The right-hand side of Figure 6 shows the number of located events per day during start of excavation (blue vertical arrow) and during stepwise cementation (red vertical arrows). In total, more than six million AE events were recorded and localized. Highest event rates are found during excavation and cementation, when more than 170,000 events are recorded and located per day (blue vertical arrow). It is shown that the activity starts in formerly inactive homogenous salt rock as soon as excavation is starting (left-hand side of Figure 6). After excavation and also after cementation is finished, the activity rate dropped nearly to the level of background seismicity rates (approximately 100 to 300 events/day). During cementation, the $\mathrm{AE}$ activity was limited to a zone approximately $0.5 \mathrm{~m}$ from the newly created borehole outlining the excavation damage zone [82]. The AE activity was extending outwards with time, but was also limited within a zone approximately $2 \mathrm{~m}$ from the borehole boundary. During excavation, AE events outlined the migration of humidity and temperature from the cementation into the rock.
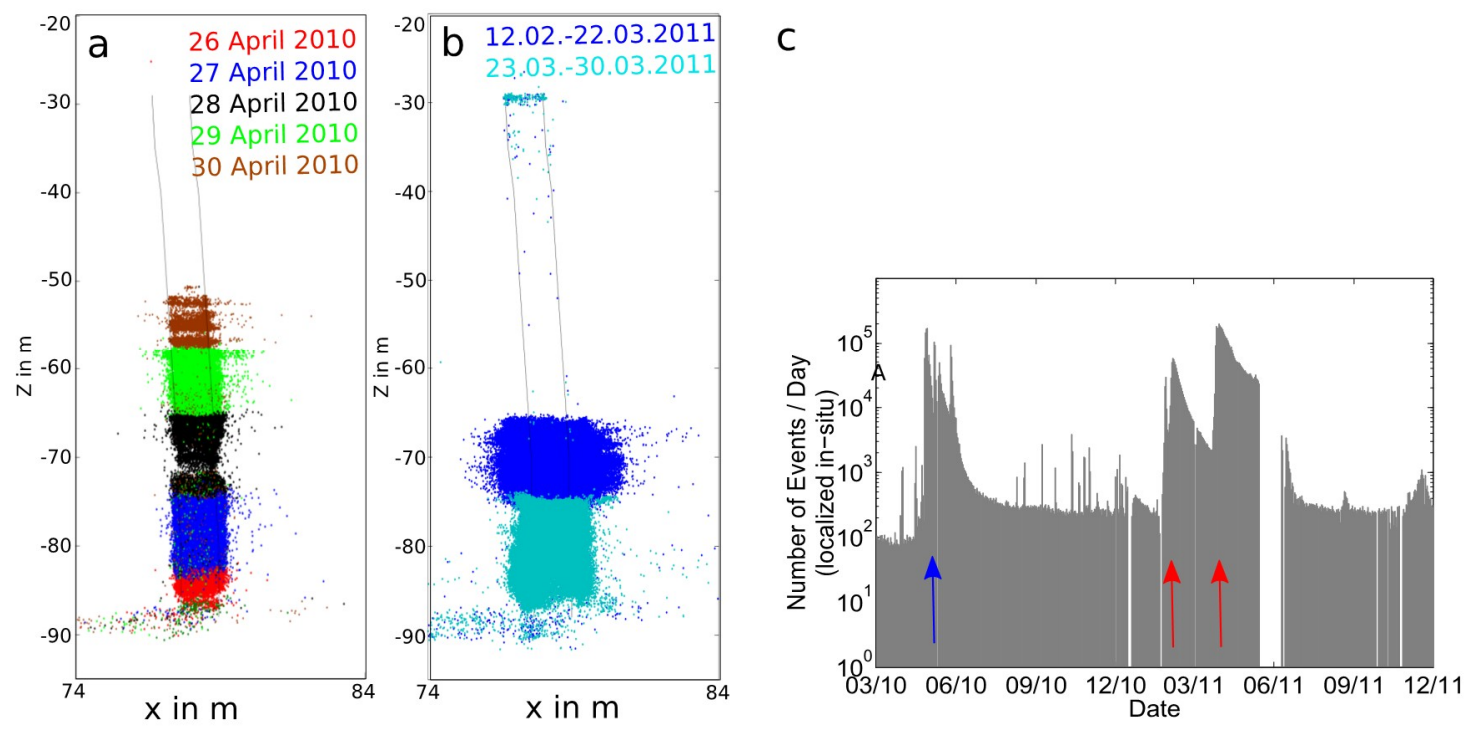

Figure 6. Temporal and spatial distribution of AE events in Merkers 1 experiment. The location of $\mathrm{AE}$ events during excavation (a) and cementation (b) are given in side view projection. The number of events per day of the whole monitoring period from March 2010 to December 2011 is shown in (c). The blue and red vertical arrows indicate the start of excavation and cementation, respectively [82]. 
It should be noted that from June 2011 on the wide-diameter borehole was loaded stepwise with compressed air. The pressurization took place in several steps. Each time, when pressure was increased, the daily activity rate increased by a few hundred events.

In January 2012 at a pressure of 60 bars for the first time AE events were observed that migrate as far as $20.2 \mathrm{~m}$ from the wide-diameter borehole. Those events were concentrated on a layer with minor vertical expansion and outline the migration of gas and brine. On 24 January 2012a gas and brine breakthrough was observed at two monitoring boreholes in combination with a pressure drop from 68 bars down to 56 bars. It was discussed that the AE events represent the break down of grain boundaries (source radius of a few centimeters) during percolation of the gas and brine mixture.

Figure 7 shows AE swarm activity during gas-brine break-through in top view (Figure 7a) and a lateral view (Figure $7 \mathrm{~b}$ ). For orientation, the neighboring pillars are shown in dark grey areas in (Figure 7a). Here color-coded lines mark the most outward extension of AE activity with time, which showed a migration of approximately $0.6 \mathrm{~m}$ per day [82]. In Figure $7 \mathrm{~b}$ the cemented plug is shown in grey and the positions of AE sensors are shown by red triangles.
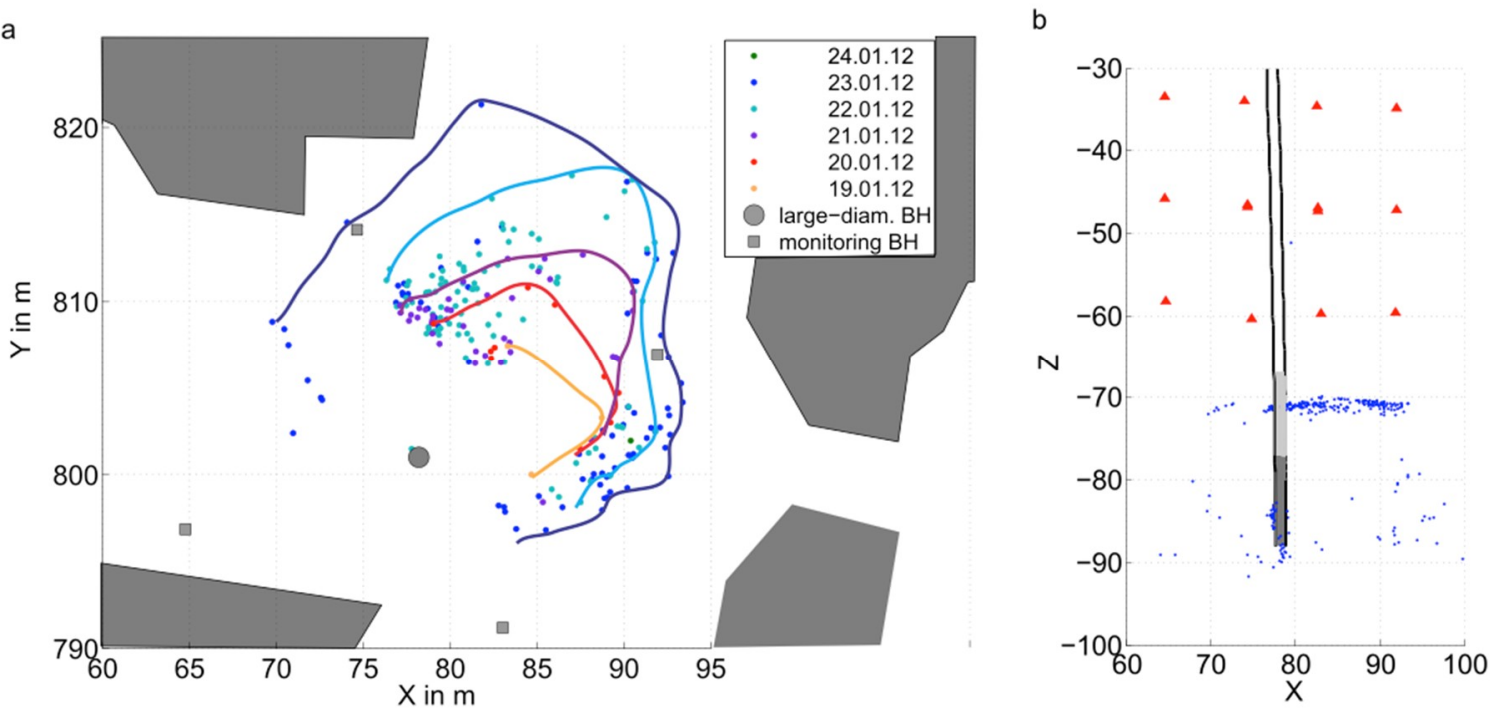

Figure 7. AE swarm activity during gas-brine break-through in map view (a) and side view (b). For orientation, the neighboring pillars are shown in dark grey in (a). Here color-coded lines mark the most outward extension of AE seismicity with time, which shows a migration of approximately $0.6 \mathrm{~m}$ per day. In (b) the cemented plug is shown in grey and the positions of AE sensors are shown by red triangles [82].

The experiment shows that quite different processes that influence the strength and the permeability of rock are successfully monitored using in situ AE monitoring technique. Not only is the influence of mechanical penetration (drilling) mapped by AE events (formation of the so-called excavation disturbed zone (EDZ)), but also the influence of environmental influences (humidity and temperature during cementation). Last but not least, the aseismical opening of a pathway for gas-brine percolation is accompanied by AE events.

\subsection{Salt Mine Morsleben in Germany}

The following example of in situ AE monitoring originated from the central section of the underground repository of Morsleben in Germany. Mining in these areas continued until the 1960s, but most of the rooms in the rock salt were mined more than 80 years ago. In this section, in situ $\mathrm{AE}$ monitoring has been performed since 1994. In the central section of the underground repository, the borehole sensors are distributed at three excavation levels and installed in 3 to $20 \mathrm{~m}$ deep boreholes. Originally, a network of 24 AE sensors monitored this section and covered an area of 
$150 \mathrm{~m} \times 100 \mathrm{~m} \times 120 \mathrm{~m}$. This network was enlarged to 48 channels and covers a rock volume of about $250 \mathrm{~m} \times 200 \mathrm{~m} \times 120 \mathrm{~m}[37,39,69]$. The average depth of the monitored volume is $400 \mathrm{~m}$. This in situ AE monitoring provides a dataset of currently approximately 15 million located events per year [92]. For most events no waveforms are stored, but only the results of real-time processing.

The aim of in situ AE monitoring is to investigate micro- and macrocracking, which are important for the evaluation of the stability of cavities and the hydraulic integrity of the rock, which is of special interest in the case of an underground disposal of hazardous waste in salt rock [39]. Figure 8 shows a cross section (sketch) through the central part perpendicular to the average direction of strike, where cavities in rock salt were mined beneath thick anhydrite blocks. The actual geological situation and the arrangement of cavities is more complicated and strongly varying along the strike. Stress redistribution causes high AE activity at the walls of the cavities (in the EDZ) particularly, where cavities are close to one another and at the boundary between rock salt and anhydrite [39].

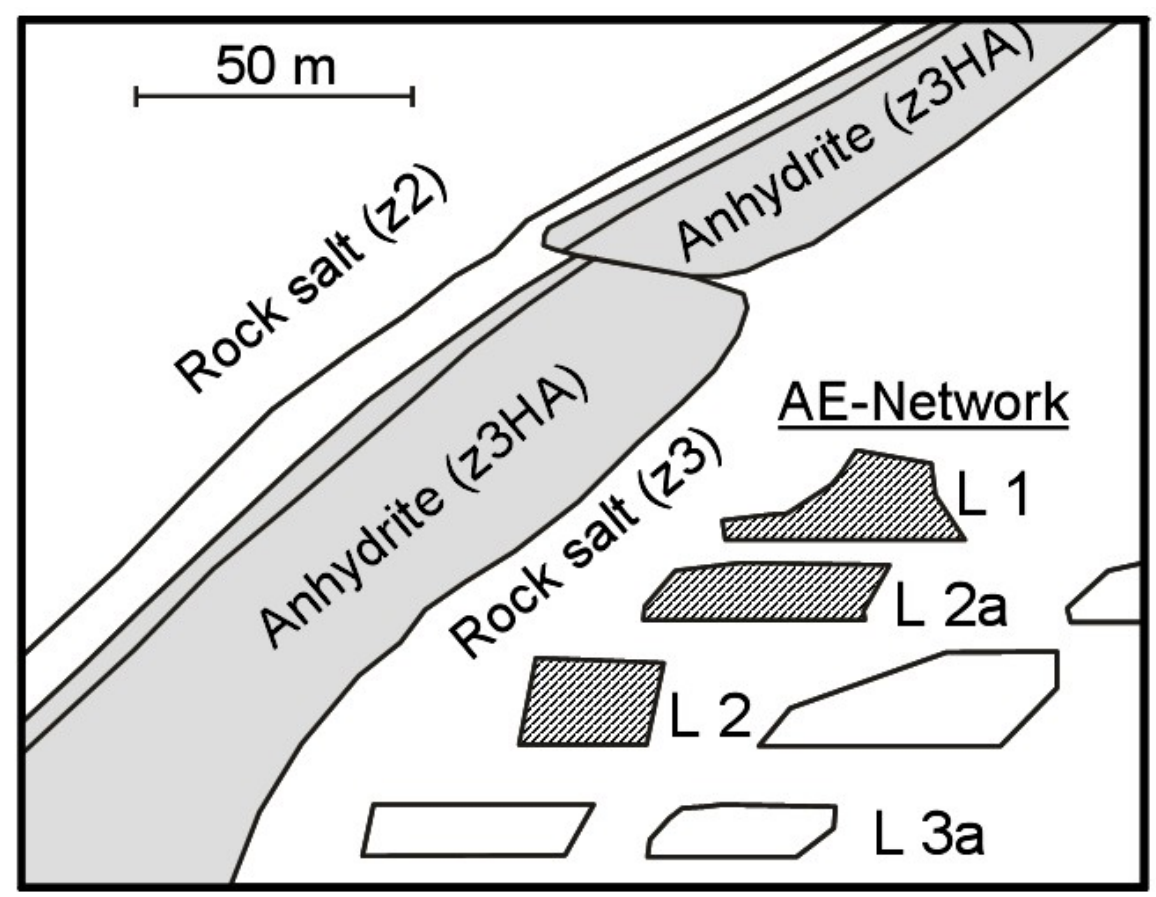

Figure 8. Sketch of geology and geometry of rooms in the central mine segment, where the AE network was installed (levels L1 to L3) [39]. Reproduced with permission.

However, the temporal and spatial occurrence of the events differs. Apart from seasonal fluctuations that may be explained by variations in humidity, the AE activity along the walls of the cavities does not vary with time. Outside the cavities near the anhydrite border, the AE events occurred in clusters. In some cases, such clusters were repeatedly located in the same volume; in other cases, significant emission occurred only within a limited time period [37].

To maintain the integrity of the barrier to the top of the salt deposit and the stability of the rooms for a long time, the rooms in the central part were backfilled with salt concrete from September 2003 to January 2011. During and after backfilling, the rock in the vicinity of these rooms were additionally loaded due to thermally induced stresses by released heat during hydration of the salted concrete for a period of several months to several years. Figure 9 shows the development of the located AE events per hour over a very long period, including the time before backfilling. One recognizes the strong increase of the microcracking activity up to approximately 1200 events per hour with beginning of the backfilling starting from September 2003 [92]. 


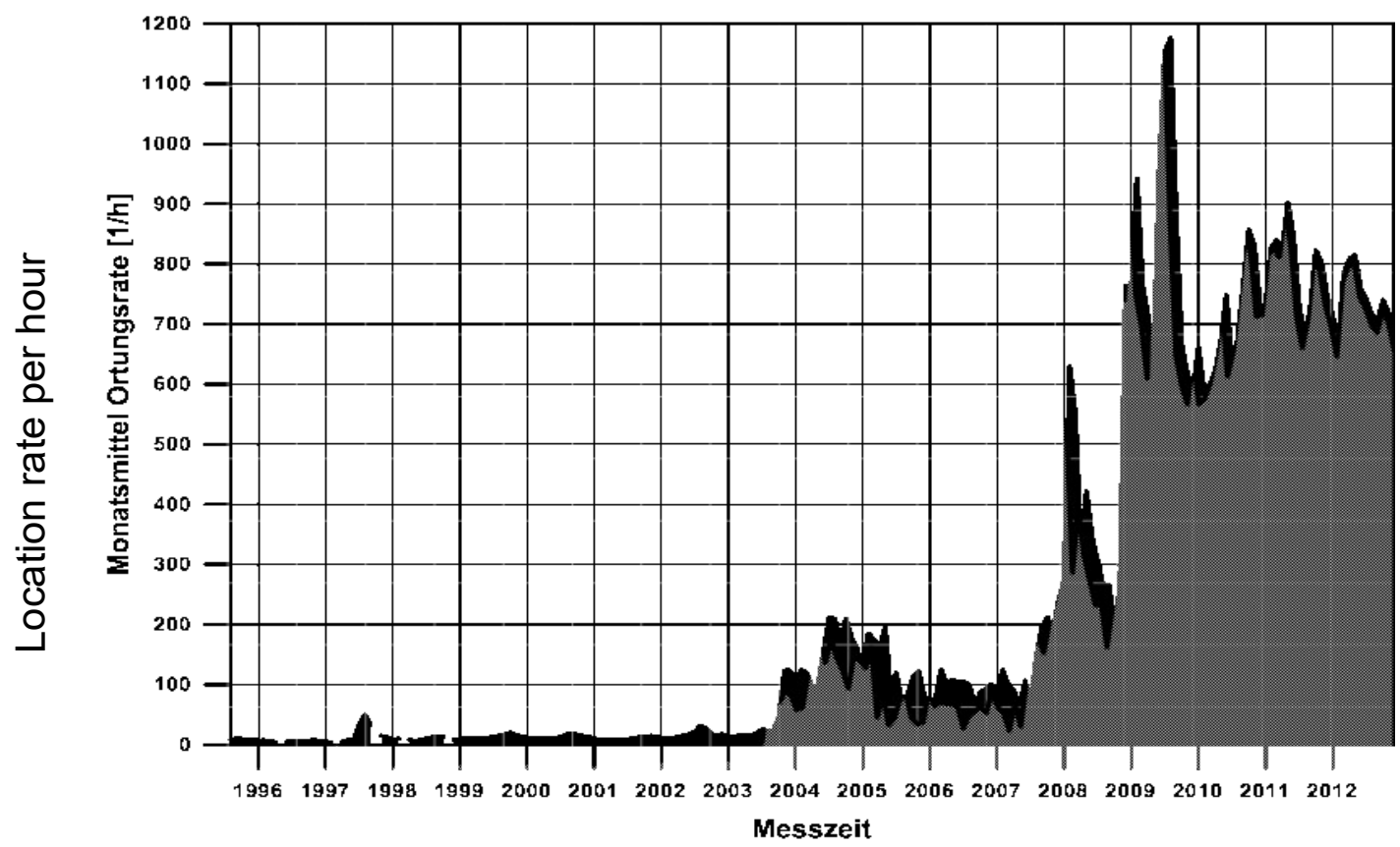

Figure 9. Development of the location rate in the time period from August 1995 to December 2012 in the area of the AE network in the central part of the salt mine Morsleben [92]. Reproduced with permission.

Figure 10 shows a perspective view of the central part of the salt mine Bartensleben with the rooms at Levels L1 to L3. The located AE events and the AE borehole sensors are marked by blue and red dots, respectively. The AE events were located during backfilling within a time period of two days in May 2010. It can be stated, that most of the activity took place near the cavities with especially high AE activity at the roof of the cavities [92].

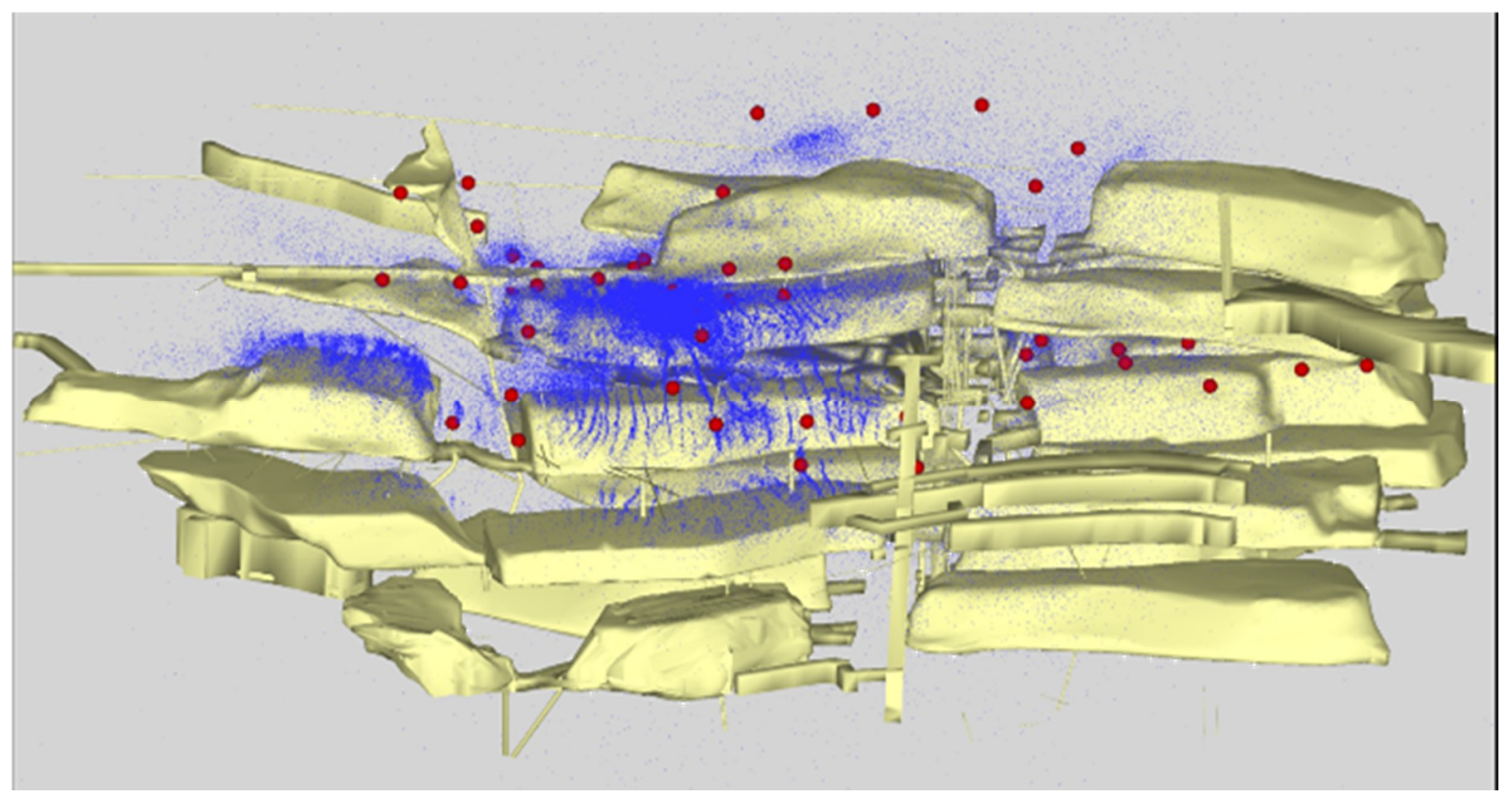

Figure 10. Perspective view of the central part of the salt mine Bartensleben (Levels L1 to L3) with location of AE events (blue dots) and AE borehole sensors (red dots). The area shown has an extension of about $300 \mathrm{~m}$ in the N-S direction and $240 \mathrm{~m}$ in height. The AE events were located within 2 days in May 2010 (see https:/ / www.bgr.bund.de) [92]. Reproduced with permission. 
Almost a year after backfilling of the cavities from 2003, AE events are distributed with distinctive stripe shapes above cavities at different depth levels (see Figure 11). The physical forces driving the creation of these stripes are still unknown. One possible explanation might be that these spatial patterns of the AE activity originated from the extensional stress developing in the cavities roofs. This strip-shaped pattern runs transversely to the longitudinal axis of the excavation in the ridge area of the room [92].

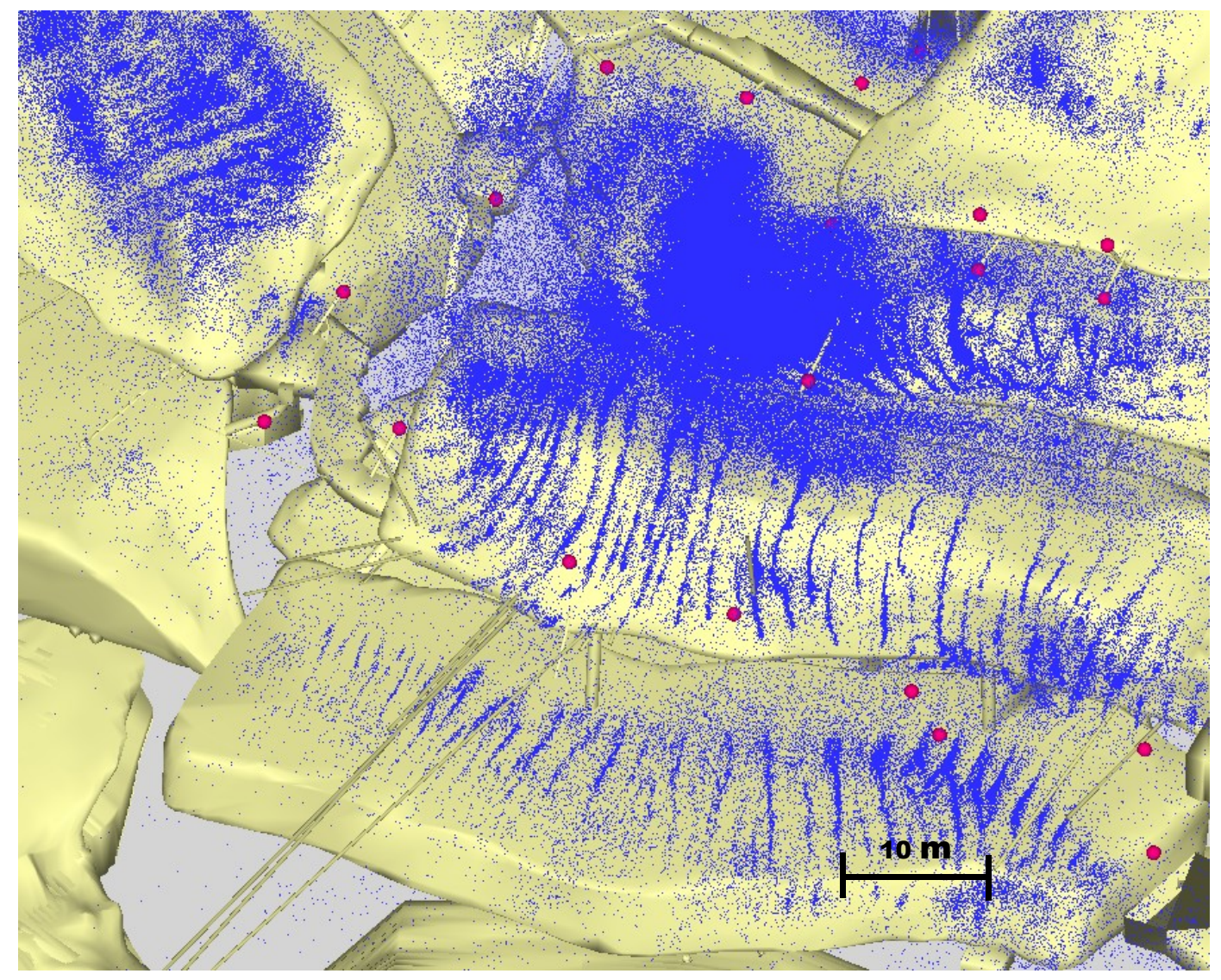

Figure 11. Patterns of approximately parallel stripes of AE activity over the ridges of backfilled excavation chambers. The view is downwards in diagonal direction [92]. Reproduced with permission.

In situ AE monitoring in the salt mine Morsleben provide a very large and unique dataset of approximately 100 million located $\mathrm{AE}$ events and it offers a wide range of options for evaluating fracture processes in a salt mine. In conclusion, the AE activity in salt rock is detected around open cavities and at the boundaries between different rock types. Creep processes cause high AE activity due to high deviatoric stresses at the walls of the cavities in the EDZ. This kind of AE activity is interpreted as ongoing deformation (convergence) in the vicinity of the open cavities and it is always present until convergence has been stopped, e.g., by backfilling of the open cavities. Apart from seasonal fluctuations due to the variation of humidity, the AE activity does not vary with time.

Because of its ductile behavior, rock salt is usually capable of performing creep deformation without occurrence of microcracking at stresses below the so-called dilatancy boundary. Above the dilatancy boundary, microcracking occurs. Most of the microcracks occur on grain boundaries and form no continuous macroscopic fractures. Deviatoric stresses above the dilatancy boundary result in the growth and opening of these microcracks, which are mainly responsible for dilatancy and the increase of permeability for fluids [37].

Although these microcracks have small dimensions in the order of the grain size (millimeter or centimeter) of the rock salt, in the course of time in dilatant zones microcracks may join and form 
macroscopic fractures especially in pillars between open cavities and in locations of high stress due to the edges of rooms, which are superposed in different levels. In such highly stressed zones, local instabilities may arise as spalling from the walls and roof falls. In this case, the EDZ migrates into the intact rock salt. AE activity in the EDZ will be stopped not before the open cavities are closed by convergence or backfilling. Closed cavities stabilize the environmental rock and microcrack formation will be stopped [92].

Figure 12 displays the evolution of AE location rates per hour (average of one day) and the evolution of temperature in the open space beneath the roof of a room. Backfilling started in October 2003 and the room was filled completely by the end of March 2004. Clearly, a very good correlation of AE location rates and temperature could be stated in the first three month. The general increase of temperature resulted from the heating due to the concrete setting of hydration. The peaks of the curve are caused by the fact that the fresh concrete cools down the surface of the concrete body during the working week. At the weekend backfilling is interrupted and temperature rises quickly until the beginning of the next week. The quick temperature increase is accompanied by a very sharp and high increase in the location rate of AE events characterizing the intensity of microcrack processes taking place. When temperatures decreased after the weekend, the location rates also decreased instantaneously indicating that the microcrack activity was generated by thermoelastic effects due to the heating of the rock mass by the setting of the concrete.

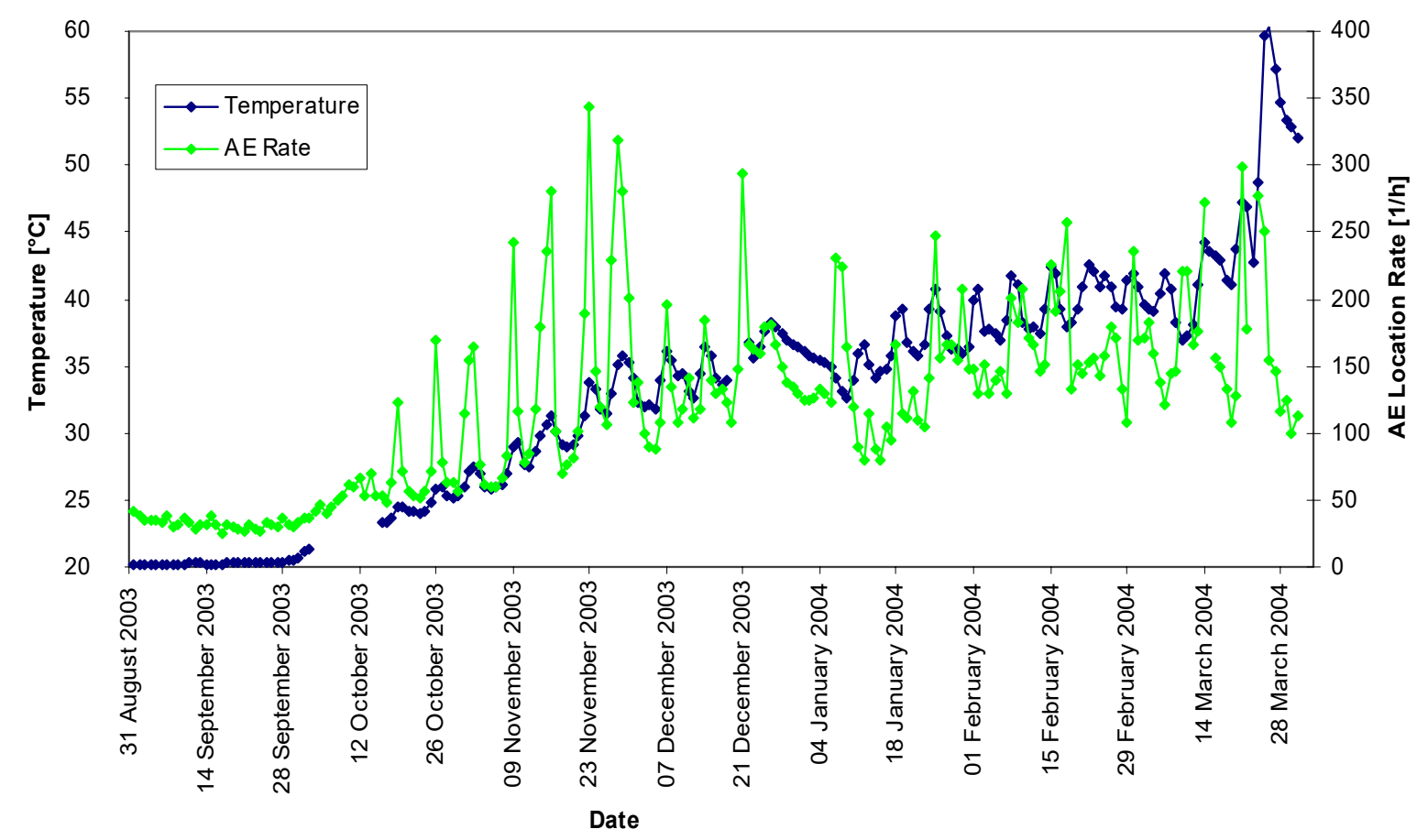

Figure 12. AE location rate and temperature in a room in the central part of the salt mine Bartensleben during backfilling [38].

Becker et al. [72] compare in a study the spatio-temporal evolution of the AE event distribution (Figure 12) with results from a 2D-finite element study of the evolving stress field well constrained by the known geometry of the structure and the material properties. They found out that for the first five thermal loading cycles a pronounced Kaiser effect can be observed. The so called Felicity Ratio is the ratio of the $\mathrm{AE}$ onset stress value to the previous peak stress [93]. It is a measure of the quality of the Kaiser effect with a value of 1 indicating a perfect stress memory effect. The observed Felicity Ratio of greater than 0.96 for the first five loading cycles indicates a very pronounced Kaiser effect. The deviation from the Kaiser effect during later loading cycles seems to be caused by the initiation of a 
planar macroscopic crack, which is subsequently reactivated. AE activity tends to concentrate along this macrocrack.

\section{In Situ AE Monitoring in Gold Mines}

\subsection{Gold Mine Cook 4 in South Africa}

Performing in situ AE monitoring inside the deep mines in South Africa is challenging, because these mines are active working mines that come with an especially harsh environment. What is beneficial for AE monitoring is the hard rock environment that allows to observe seismic waves with frequencies far above $25 \mathrm{kHz}$ from significant distances from more than $100 \mathrm{~m}$ [36]. For SHM, in situ AE monitoring was shown to be a valuable tool, because damage zones prone to failure can be identified beforehand and rock bursts can be analyzed in great detail after.

The SATREPS project [33], that took place in Cooke 4 Mine, near Westonaria in South Africa at about $1 \mathrm{~km}$ depth demonstrated how to monitor a mining front in quartzite from afar, using a network of 24 field AE sensors and 6 triaxial accelerometers installed in development tunnels approximately $20 \mathrm{~m}$ to $50 \mathrm{~m}$ below the stope (network dimension $95 \mathrm{~m} \times 50 \mathrm{~m} \times 30 \mathrm{~m}$, monitoring area $100 \mathrm{~m} \times 180 \mathrm{~m} \times 50 \mathrm{~m}$ ). Figure 13 shows configuration of the in situ AE monitoring system installed $1 \mathrm{~km}$ beneath the ground in the Cooke 4 shaft. This figure shows the top view of the stope and the positions of sensors. The black squares denote the positions of the borehole sensors. The hatched area represents the excavated area. The mining faces are typically $30 \mathrm{~m}$ across and 1 to $2 \mathrm{~m}$ high, and the stope is sub-horizontal orientated. By daily blasting, the mining face advances to the north by about $10 \mathrm{~m}$ per month (red arrows). The mining face was located about $20 \mathrm{~m}$ above the AE network.

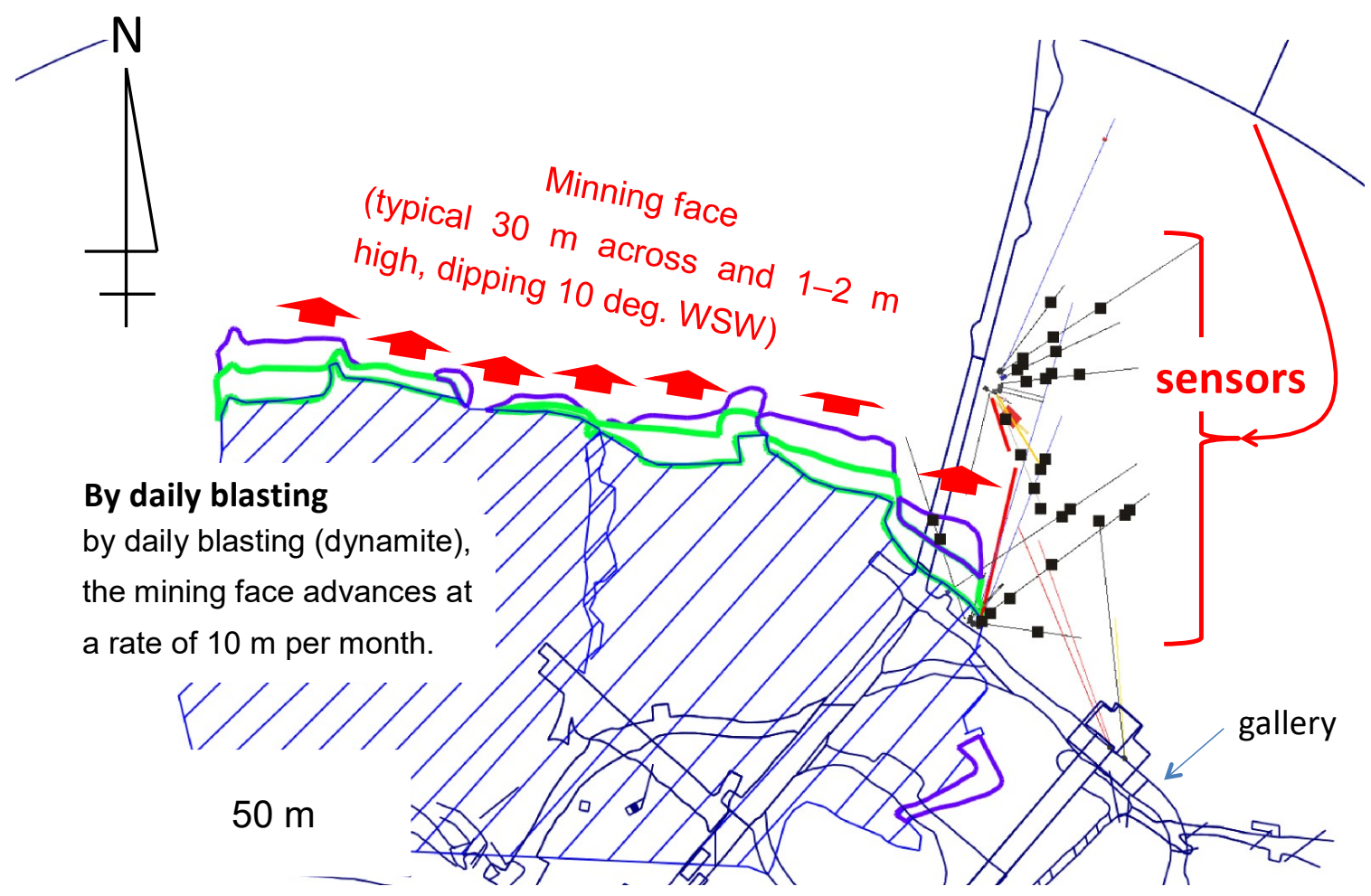

Figure 13. Top view of the stope and the positions of the borehole sensors (black squares). The shaded area represents the excavated area. The mining faces are typically $30 \mathrm{~m}$ across and 1 to $2 \mathrm{~m}$ high and the stope is sub-horizontal orientated. By daily blasting, the mining face advances to the north by about $10 \mathrm{~m}$ per month (red arrows) [34].

Over a time period from 11 July 2011 to 24 August 2011 (approximately 50 days), about 290,000 AE events were recorded in trigger mode recording and localized using the joint hypocenter determination 
(JHD) approach and double-difference re-localization. The moment magnitudes $\mathrm{M}_{\mathrm{W}}$ of events ranged from -3.7 to 1.0 [53]. Figure 14 shows the JHD result of 289,015 events, that had RMS residuals smaller than $1.0 \mathrm{~ms}$ in a top view (a) at an elevation of $690 \mathrm{~m}$ above sea level (about $1 \mathrm{~km}$ beneath ground), and (b) NNE-SSW vertical projection viewed from the west.

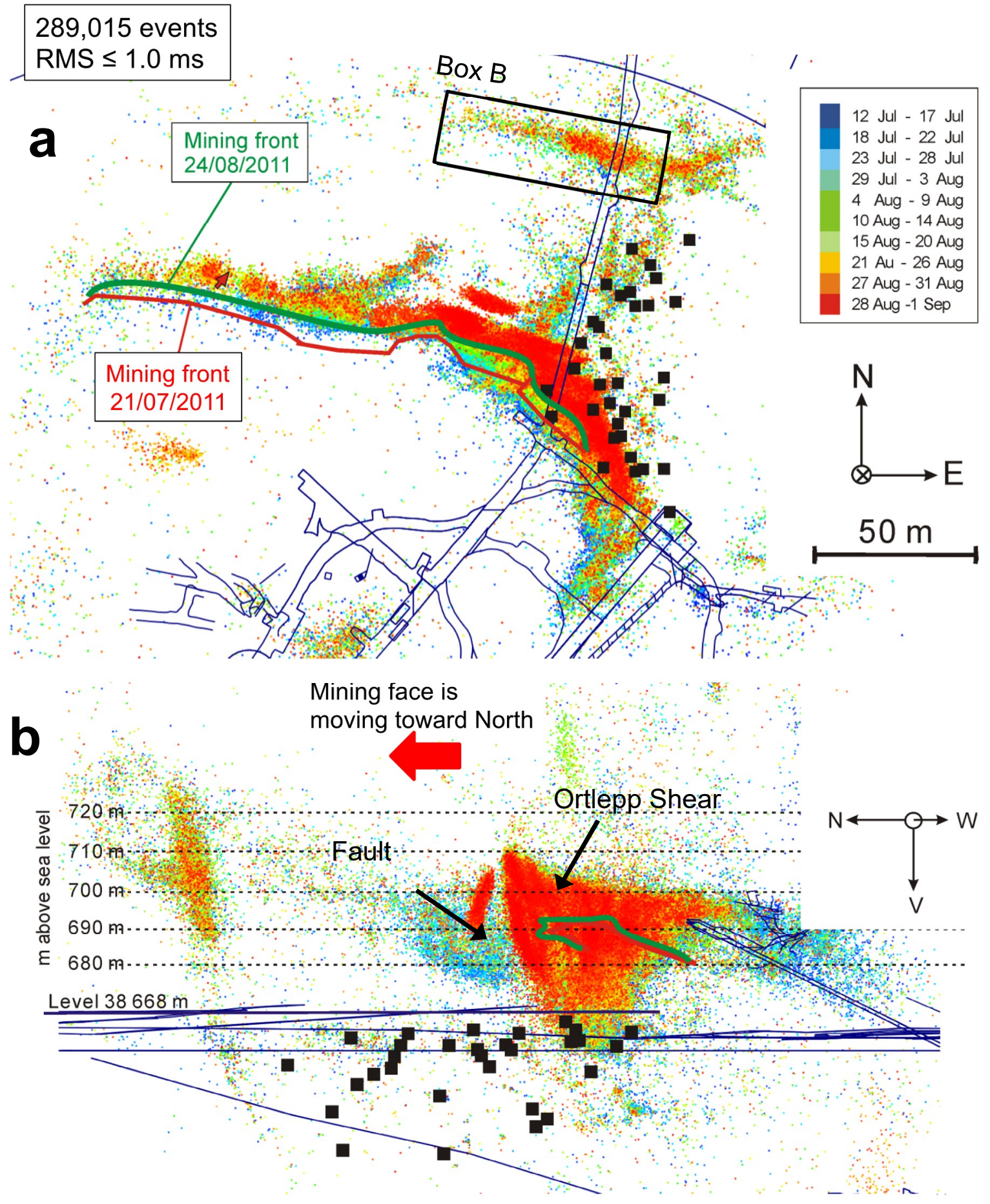

Figure 14. Source locations of AE events determined by JHD in a top view (a) at an elevation of $690 \mathrm{~m}$ above sea level (about $1 \mathrm{~km}$ beneath ground), and (b) NNE-SSW vertical projection viewed from the west. Black squares indicate AE sensor locations. Thick cyan and red lines represent positions of the mining face on 21 July and 24 August 2011, respectively. Blue lines are outlines of the mining infrastructure. Box B outlines the area that is shown in Figure 15 in detail. A total of 289,015 AE events were located, with their dates of occurrence indicated by the color scale [34]. 
Black squares indicate AE sensor locations. Thick cyan and red lines represent positions of the mining face on 21st July and 24th August 2011 respectively. Blue lines are outlines of the mining infrastructure. The 289,015 AE events were located, with their dates of occurrence indicated by the color scale. Nearly all (90\%) of the AE events occurred in a zone extending about $20 \mathrm{~m}$ ahead (north) of the active mining face, forming what is referred to as the stope-front cloud. AE events clearly clustered on structures' outlining planes of localized damage, which is why the authors referred to the monitoring as an advanced $\mathrm{AE}$ mapping technique.

Naoi et al. [84-86] relocated clustered AE events by using the double difference technique [94]. After a pre-selection of events, the cross-correlation technique for all event pairs whose inter-event distance was smaller than $4 \mathrm{~m}$ was applied. The number of events in Box B in Figure 14a before relocation was about 10,688. The number of events successfully relocated as AE events was 10,337. Figure 15a,b show relocated AE events in projections onto the $\mathrm{x}-\mathrm{y}$ plane and $\mathrm{x}-\mathrm{z}$ plane, respectively. A local coordinate system aligned with the clear discernible plane is used. The $\mathrm{x}$ coordinate is along the strike direction (positive eastward), the y coordinate is in the normal direction to the plane (positive northward), and the $\mathrm{z}$ coordinate is along the dip direction (positive upward). Figure 15c shows projections onto the $\mathrm{x}-\mathrm{y}$ plane for $\mathrm{z}$ coordinate between $13.5 \mathrm{~m}$ to $34.5 \mathrm{~m}$ in steps of $3 \mathrm{~m}$ thickness in the $\mathrm{z}$ direction. Blue dots are clustered AE events (approximately 4900) defined at the plane, which are situated in the red dashed frames in (a) and (c). Gray dots are other events, which belongs not to the cluster. The AE hypocenters projected onto $x-y$ planes exhibit clear traces continuous over several meters or more. It was shown that the events of this cluster correspond to the Zebra fault, a local fault.
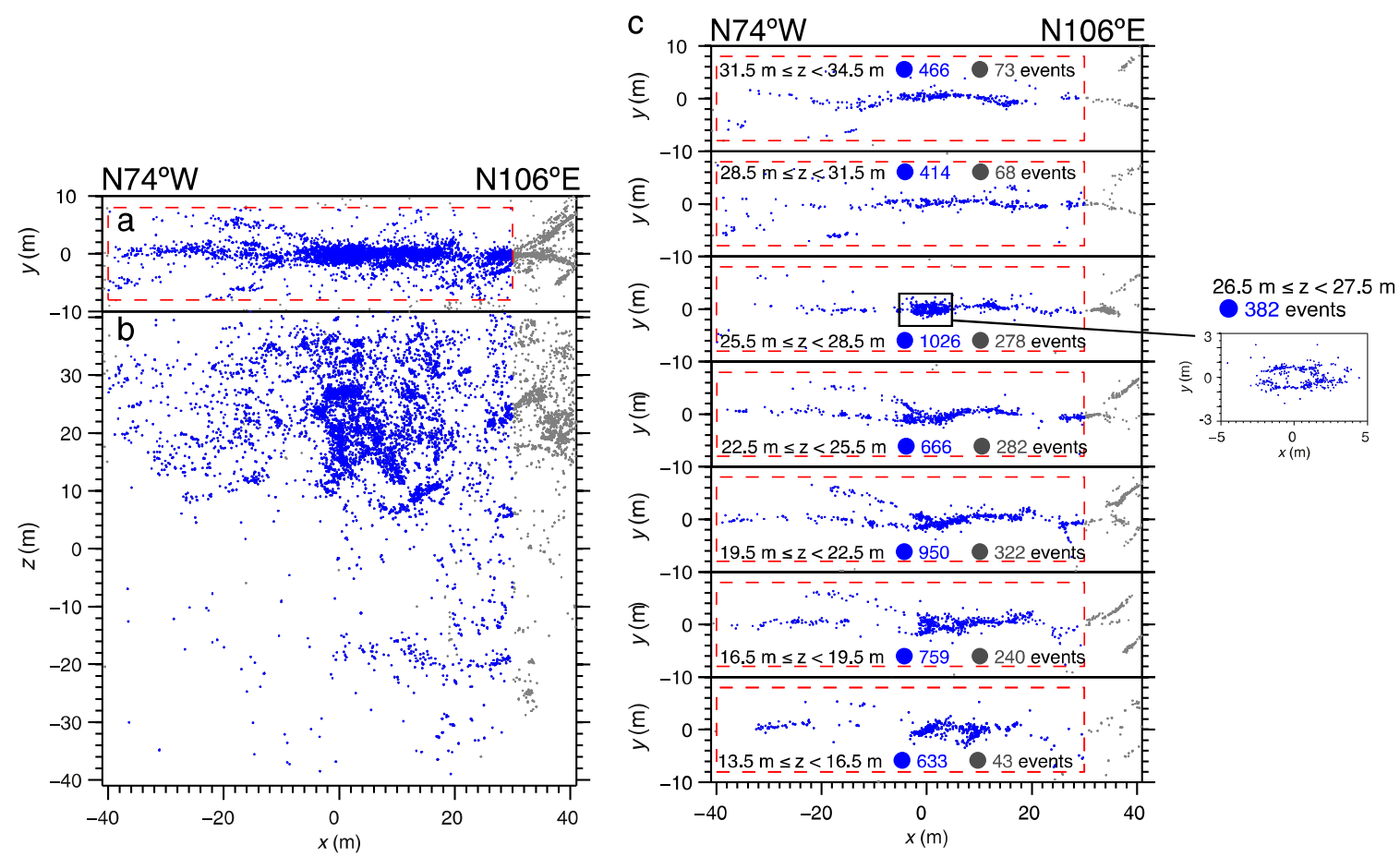

Figure 15. Close up of area marked by Box B in Figure 13. The relocated AE events in projections onto the $x-y$ plane (a) and $x-z$ plane (b) are shown. A local coordinate system aligned with clear discernible plane is used. $x$ coordinate is along strike direction (positive eastward), $y$ coordinate is in normal direction to the plane (positive northward), and $\mathrm{z}$ coordinate is along dip direction (positive upward). (c) Shows projections onto the $x-y$ plane for $z$ coordinate between $13.5 \mathrm{~m}$ to $34.5 \mathrm{~m}$ in steps of $3 \mathrm{~m}$ thickness in the $\mathrm{z}$ direction. Blue dots are clustered, which are located in the red dashed frames in $(\mathbf{a}, \mathbf{c})$. Gray dots are other events [84].

The information gained from studying the characteristics of AE event on such structures revealed in-depth information useful for risk assessment and stope planning. For example, the formation of 
Ortlepp shear fractures [95,96] due to the approaching stope front could be observed (see Figure 14b); $\mathrm{AE}$ activity picking up on the newly created formation already, when the mining front was still more than $20 \mathrm{~m}$ away [34].

At the same time, pre-existing discontinuities such as faults or dikes that get seismically activated by the stress re-distribution due to the excavation were also identified [34,84]. Higher-order features such as branches and step-overs could be observed owing to the high localization certainty. Detailed analysis of AE event properties including a b-value study revealed that both quasi-static slip [85] as well as dynamic slip events is observed on faults [84].

Interestingly the frequent observation of repeating AE events on faults monitored during the SATRAPS project suggests that AE events on faults loaded by stress-redistribution due to mining undergo a similar process as tectonic faults subject to tectonic stresses [86]. Note that both Ortlepp shear fractures as well as the re-activation of faults cause on a regular basis violent rock burst events (M1 to M4), which are a significant threat to people working underground [96-98].

\subsection{Gold Mine Mponeng in South Africa}

The joint Japanese-German Underground Acoustic Emission Research project (JAGUARS) (see Table 3) in South Africa measures AE events in the frequency range from $700 \mathrm{~Hz}$ to $200 \mathrm{kHz}$. In the JAGUARS project [73] conducted in Mponeng Gold Mine in Carltonville in South Africa in $3.3 \mathrm{~km}$ depth the full evolution of a rock burst with moment magnitude $M_{W}=1.9$ could be monitored using an in situ AE monitoring network. The JAGUARS network was installed in spring 2007.

Table 3. Group members of the joint Japanese-German Underground Acoustic Emission Research in South Africa (JAGUARS) project [36,73].

\begin{tabular}{cc}
\hline Institute & Main Contributors \\
\hline $\begin{array}{c}\text { Jarthquake Research Institute of the University of Tokyo } \\
\text { Tohoku University } \\
\text { Ritsumeikan University }\end{array}$ & $\begin{array}{c}\text { M. Nakatani, M. Naoi; } \\
\text { Y. Yabe } \\
\text { Germany } \\
\text { H. Ogasawara }\end{array}$ \\
$\begin{array}{c}\text { GFZ: German Research Centre for Geosciences Potsdam } \\
\text { GMuG mbH, Bad Nauheim }\end{array}$ & $\begin{array}{c}\text { K. Plenkers, G. Kwiatek, G. Dresen, S. Stanchits } \\
\text { J. Philipp }\end{array}$ \\
\hline $\begin{array}{c}\text { South Africa } \\
\text { AngloGoldAshanti Ltd. } \\
\text { Institute of Mine Seismology (IMS), Stellenbosch } \\
\text { Council for Scientific and Industrial Research (CSIR), } \\
\text { Johannesburg }\end{array}$ & $\begin{array}{c}\text { G. Morema, T. Ward } \\
\text { C. Miller, T. Nortje, R. Carstens } \\
\text { E. Pinder, G. van Aswegen } \\
\text { S. Spottiswoode }\end{array}$ \\
\hline
\end{tabular}

The gold is mined from the Witwatersrand formation. The gold-carrying sedimentary layer (Ventersdorp Contact Reef) is embedded in a thick series of quartzite, dipping with $26.5^{\circ}$ toward the south-east, and reaches a thickness of 0.5 to $1 \mathrm{~m}$. The JAGUARS network is located approximately $90 \mathrm{~m}$ below the reef, next to a gabbroic dike (Pink-Green (PG) dike, Figure 16). This dominant geological feature is $30 \mathrm{~m}$ wide and dips nearly vertically. It cuts through the reef and serves as a support pillar for the exploitation.

Naoi et al. [99] estimated the seismic velocities of rock types in the vicinity of the network from velocity tomography using AE transmission measurements. For the quartzite host rock, Naoi et al. [99] estimated seismic velocities of $v_{P}=6.2 \mathrm{~km} / \mathrm{s}$ for $P$ waves and $v_{S}=3.8 \mathrm{~km} / \mathrm{s}$ for $S$ waves. The velocities within the pink-green dike were found to be slightly higher, with $v_{P}=6.9 \mathrm{~km} / \mathrm{s}$ and $v_{S}=3.9 \mathrm{~km} / \mathrm{s}$.

Mining in the vicinity of the JAGUARS network (Figure 16) started in early 2007. The network focuses on the dike-host rock contact close to the mining front, where larger events with magnitudes 
up to $M_{W}=3.0$ were expected due to stress concentration induced by mining (personal conversation with S. Spottiswoode, 2009). The seismic network is consisting of 8 borehole AE sensors and one triaxial accelerometer. All sensors were installed in short boreholes of $6 \mathrm{~m}$ to $15 \mathrm{~m}$ length. The data were recorded in trigger-mode recording.

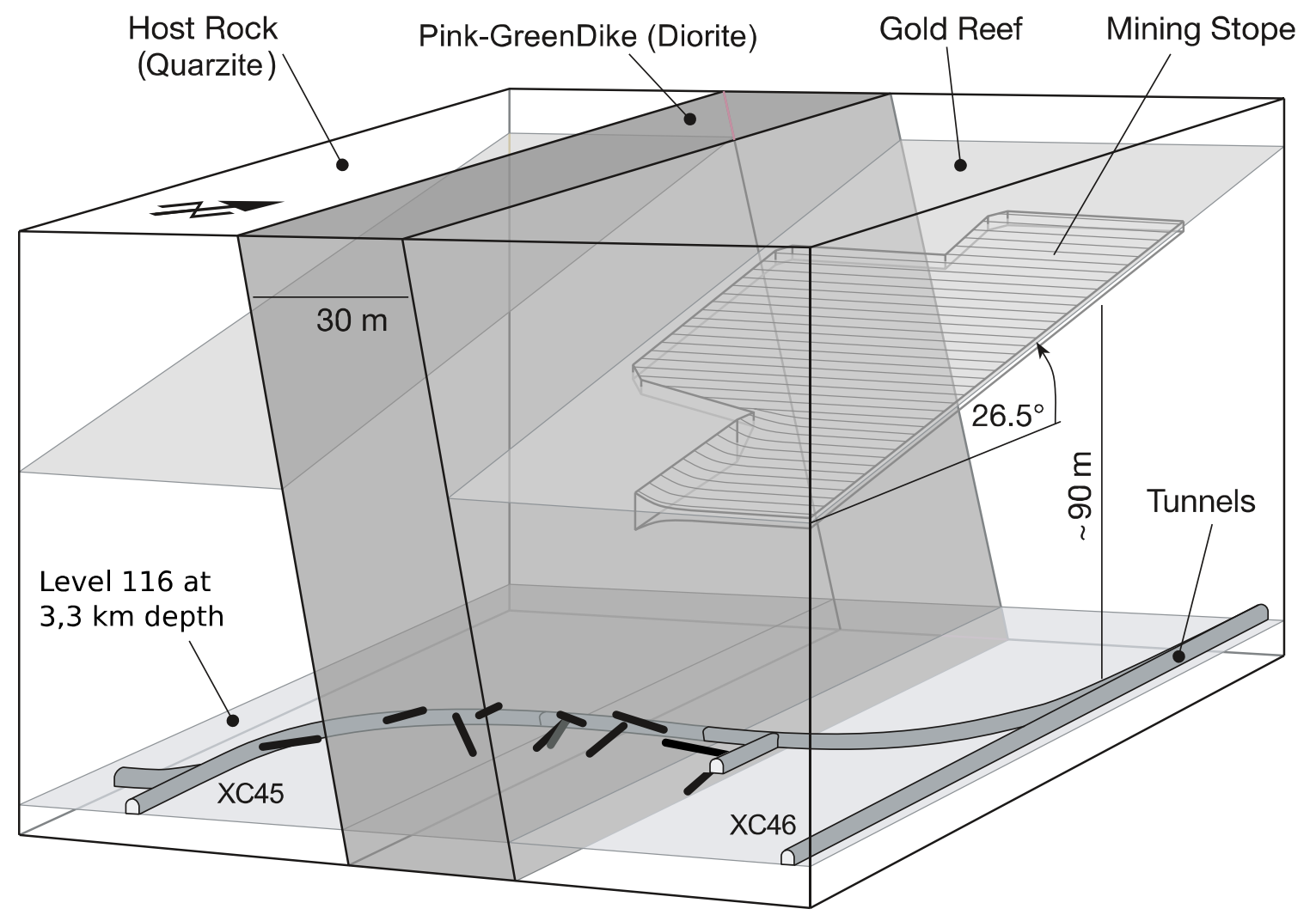

Figure 16. Sketch of the location of the JAGUARS network in the Mponeng gold mine and its surrounding geologic formations. The JAGUARS network is located at $3540 \mathrm{~m}$ depth. The sensors are located in boreholes, that are shown as bold black lines. The Pink-Green (PG) dike is shown in gray. The gold reef with active mining located above the JAGUARS network is shown in light gray. The mining stope width is $0.5 \mathrm{~m}$ to $1 \mathrm{~m}$. The development tunnels XC45 and XC46 are shown in dark gray [52]. Reproduced with permission.

The stress changes owing to the approaching mining front on the PG dyke are modeled by Ziegler [77]. A main shock with magnitude of $M_{W}=1.9$ occurred on 27 December 2007 in the center of the AE monitoring network [33,36,74]. Naoi et al. [74] manually picked P- and S-wave arrival times to locate more than 20,000 AE events, that occurred within 150 hours, following the main shock. The location error for events within a radius of about $40 \mathrm{~m}$ of the center of the AE network was less than $1 \mathrm{~m}$. Most of the AE events from this period occurred within $50 \mathrm{~m}$ to $100 \mathrm{~m}$ of the network, where the spatial coverage of the network is best. The events contain signals with a broad range of high frequencies, which allowed the sensitivity of the network toward very high frequencies above $25 \mathrm{kHz}$ to be analysed in greater detail $[36,52]$. Owing to the resulting excellent recording of the aftershock AE event sequence with most $\mathrm{AE}$ events after the main shock, the rupture process and the rupture plane could be studied in great detail.

The spatial distribution of 9,444 aftershocks is shown in map view in Figure 17a. The main shock hypocenter is shown by a grey star. The positions of cross sections I to IV are shown by magenta rectangulars. In Figure $17 \mathrm{~b}$ the cross sections are presented the location of manual re-located AE events in a side-view. The PG dyke is shown by two grey lines. The re-located events reveal that the rupture plane started within the PG dyke, but reached the geological boundary, where branching and bending 
occurred. Secondary features (marked with VII and IX) are observed that likely correspond to the rupture of major aftershocks.
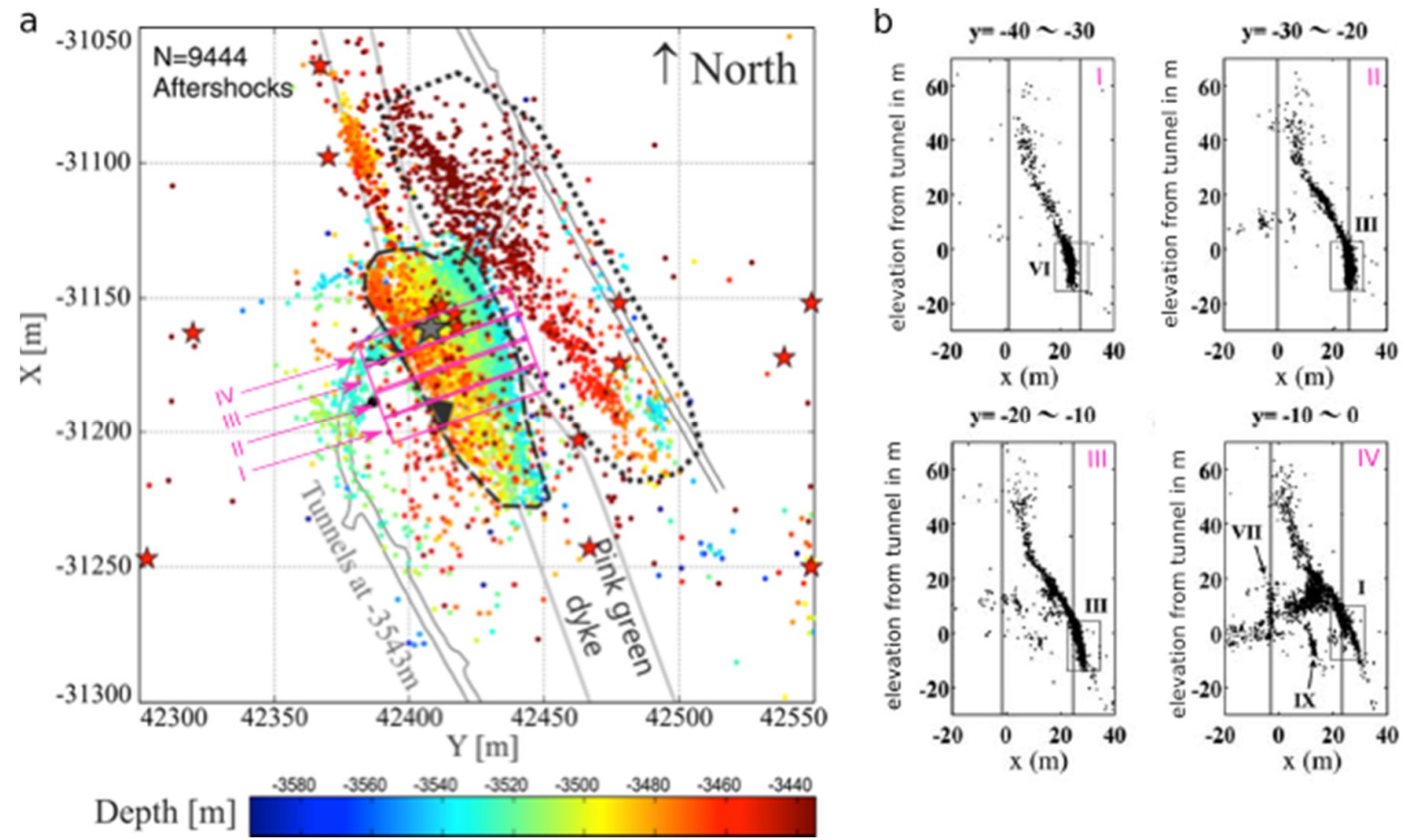

Figure 17. Mainshock-Aftershock sequence from 27 December 2007 recorded by the JAGUARS network. The spatial distribution of 9,444 aftershocks is shown in map view in (a). These aftershocks comprise a subset of the 25,000 aftershocks recorded which come with small residuals of the automatic locations. The mainshock location is shown by a grey star. Red stars show the location of all aftershocks recorded by the in-mine geophone network. The event depth (shaft depth) is color-coded, which shows that aftershocks were triggered not only on rupture plane, but also at the stope face above the mainshock. The positions of cross sections I to IV are shown by magenta rectangulars. In (b) cross sections are presented that show the location of manual re-located AE events in side-view. The PG dyke is shown by two grey lines.

Yabe et al. [78] showed that the aftershock AE events clearly delineated a plane in the PG dike with a strike of N22W and a dip of $68^{\circ}$ toward N68E (Figure 17). Because waveforms of the main shock recorded by the $\mathrm{AE}$ network were saturated in $\mathrm{AE}$ recordings, the main shock was analyzed using waveform data of the in-mine geophone network. Naoi et al. [74] were able to resolve the complexity of the rupture plane (approximately extension $100 \mathrm{~m} \times 80 \mathrm{~m}$ ), which underwent branching and bending according to geological heterogeneities present. Naoi et al. [74] applied the master-event location technique to locate the hypocenter of the main shock relative to the aftershock AE events. The main shock hypocenter obtained was about $30 \mathrm{~m}$ above the AE network and on the aftershock plane. The focal mechanism solution of the normal fault for the main shock using seismic waveforms recorded by the seismic network operated by the mine pointed out that one of the nodal planes agreed well with the aftershock plane. Therefore, the aftershock plane is considered to correspond to the rupture plane of the main shock plane, which demonstrates clearly that the AE aftershock activity outlines the main shock's rupture plane. Kozlowska [79] show that the aftershocks occur in areas of positive Coulomb stress change as determined using rate and state based stress modeling.

Source parameter analysis demonstrated that the aftershock AE event sequence has the same characteristics as tectonic aftershock events, i.e., they follow the Omori law [36], the Gutenberg-Richter distribution [55] and a static stress drop [16]. The magnitude ranges between -5.0 and -0.8 . The magnitude of completeness varied strongly in space, but was estimated to $M_{C}=-4.8$ in the network center [52]. 
The area of rupture initiation was subject to foreshock activity that is interpreted as the breakdown of asperities [78]. Interestingly, there are indications that AE events announce the main shock in advance. Figure 18a,b display the results of manual and automatic source location, respectively, applied to the same AE events, which are within $5 \mathrm{~m}$ of the aftershock surface. The events occurred during the periods before the main shock and within $150 \mathrm{~h}$ following the main shock. The black dashed contour represents the area of significant aftershock activity, as defined by Naoi et al. [74]. As this area can be presumed to represent the rupture area of the main shock, AE events that took place in the aftershock area and within $5 \mathrm{~m}$ of the aftershock surface before the main shock are hereafter referred to as "foreshocks". Four foreshock Clusters F1 to F4, and two aftershock Clusters A1 and A2 were identified from a concentration of manually located AE events. Both the foreshock and the aftershock clusters barely overlap one another. For comparison, the automatically located AE events, which are much more numerous than manually located ones are shown in Figure $18 \mathrm{~b}$ as a density plot.

(a) manual pick

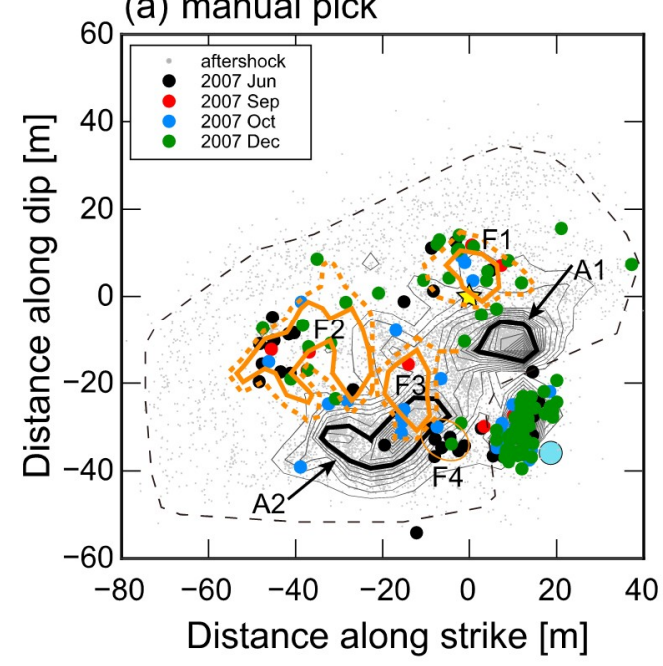

(b) automatic pick

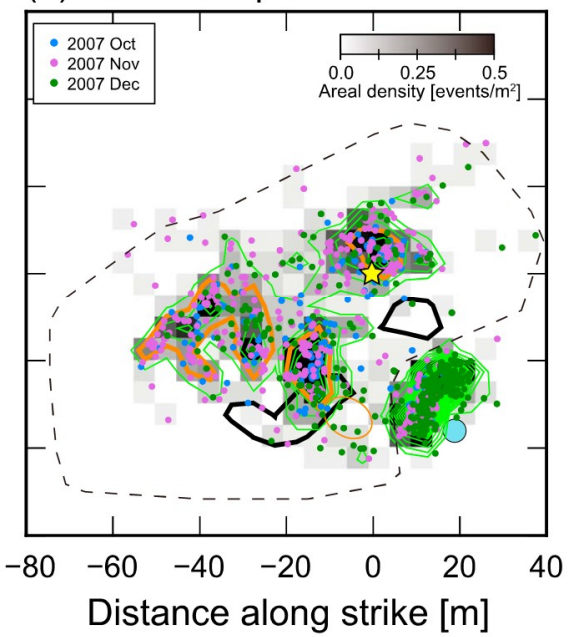

Figure 18. Foreshock activity compared to aftershock activity. (a) Distribution of the manually located AE events that occurred within $5 \mathrm{~m}$ of the aftershock surface during the period from 13 June 2007 to $150 \mathrm{~h}$ after the main shock. The yellow star indicates the main shock hypocenter. Black, red, blue, and green solid circles denote the events in June, September, October, and December, respectively. Orange and black thick solid lines enclose the foreshock clusters (F1, F2, and F3) and aftershock clusters (A1 and A2), respectively. Gray dots denote the aftershocks. Gray contours show the areal density of the aftershocks drawn by feeding areal densities in $5 \mathrm{~m} \times 5 \mathrm{~m}$ cells. The thin black dashed contour indicates the aftershock area defined by Naoi et al. [78]. The light blue solid circle is the access tunnel along which the observation network was deployed. (b) Distribution of the automatically located events that occurred before the main shock and within $5 \mathrm{~m}$ of the aftershock surface. Their densities in $5 \mathrm{~m} \times 5 \mathrm{~m}$ cells are shown by gray scale. Blue, purple, and green solid circles denote events in October, November, and December, respectively. Light green contours show the areal density of the automatically located foreshocks.

\section{In Situ AE Monitoring During Hydraulic Fracturing in Mines}

A slightly different aspect of SHM concerns the monitoring of hydraulic fracturing (HF) using in situ AE monitoring. Engineered fractures generated underground by packer probes in boreholes are facilitated in a broad variety of contexts, many of which require detailed knowledge on the damage process actively initiated. HF is a common tool for underground stress determination and provides important input for designing the stope layout and for risk assessment [100-102]. HF has become a widely used engineering tool in reservoir enhancement of geothermal systems, shale gas, or conventional oil and gas extraction as it effectively increases the permeability [103-106]. In addition, 
HF is successful in increasing the productivity in ore production e.g., HF is used in fragmenting ore bodies [107].

Several research projects have addressed HF using in situ AE monitoring or strain cells in order to increase the understanding of the rock response to HF, to study the evolution of fracture generating and predict the stimulation of existing fractures $[67,108,109]$. Two recent research projects in crystalline rock did not only record very interesting and rich data, but have pushed the limits in highly sensitive monitoring and advanced signal processing. Zang et al. [43] report on HF at the hard rock underground laboratory Äspö in Sweden (Figure 19a).

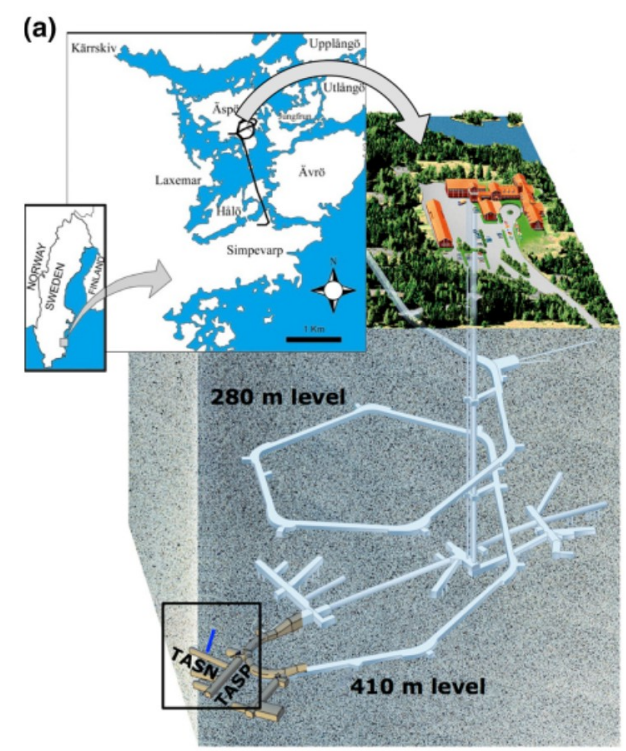

(b)

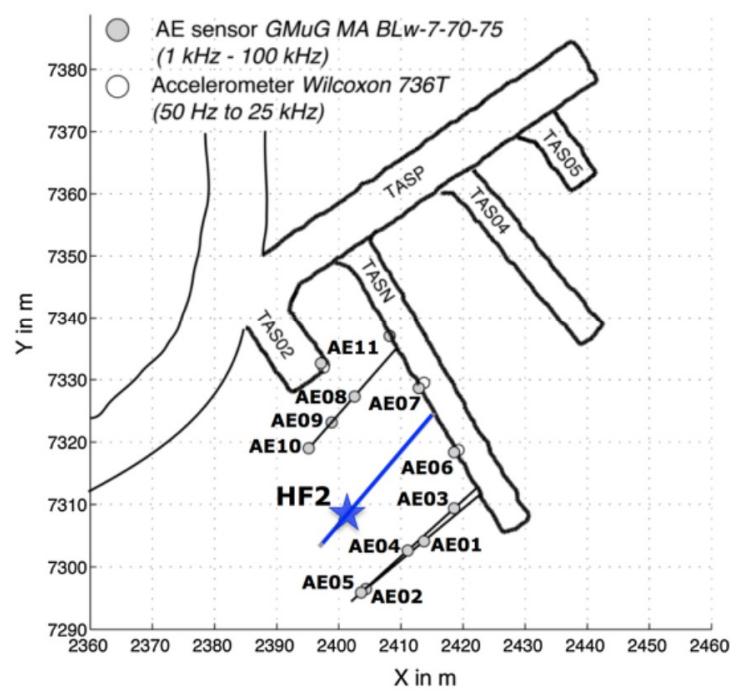

Figure 19. (a) Test site of hydraulic fracturing tests in the underground Äspö Hard Rock Laboratory in Sweden (see http:/ / www.skb.se/upload/publications/pdf/Aspo_Laboratory.pdf). (b) Location of the AE borehole sensors together with the central injection well (blue line). The blue star identifies the fluid injection segment corresponding to the hydraulic fracturing (HF2) experiment $[43,87]$.

Zang et al. [43] utilize three different monitoring networks, namely in situ AE monitoring, microseismic monitoring, and electromagnetic monitoring. Figure $19 \mathrm{~b}$ shows a top view of the AE monitoring network, which consists of 11 AE sensors of GMuG type MA BLw-7-70-75 and four Wilcoxon 736T accelerometers.

Data is recorded both in trigger mode and continuous mode (1 MHz sampling frequencies). $\mathrm{AE}$ sensors are installed in monitoring boreholes of $22 \mathrm{~m}$ to $30 \mathrm{~m}$ length parallel to the injection borehole and in short boreholes along the tunnels.

Overall, six HF stimulations are performed using three different injection schemes (continuous, progressive and pulse pressurization), from which four produced significant $\mathrm{AE}$ activity outlining the fracture orientation, extension and temporal evolution. Within 20 days, about 69,400 triggers were recorded in situ, from which many correspond to noise events due to dripping water or anthropogenic activities. The strongest AE events recorded in situ with best signal-to-noise ratio and most reliable location certainty (maximum location residual $0.3 \mathrm{~m}$ ) formed a catalog of 196 seismic events, of which all correlated in time and space directly to the HF periods. All relocated AE events are shown in a perspective view (Figure 20a) and a lateral view in a rotated coordinate system (Figure 20b) for seismically active HF stimulations (HF1 to HF4 and HF6). AE events recorded during the different fracture experiments clearly delineate the fractures and display differences between the different hydraulic fractures generated.

A faster and further expansion of AE events away from the stimulation point is observed with each subsequent re-stimulation stage outlining the damage extension. In-depth source analysis of the 
largest $\mathrm{AE}$ events including energy estimation, moment tensor inversion, source parameter estimation, and stress inversion by Kwiatek et al. [27] estimated the moment magnitude $M_{W}$ of the AE events ranges from -4.2 to -3.5 . The source analysis clearly reveals that most events correspond to shear slip events on pre-existing fractures. AE event activity starts as soon as a certain pressure level is reached. First optimum oriented fault planes fail but, overall, differently oriented fault planes are observed. Stress inversion reveals stress rotation during and after the stimulation.
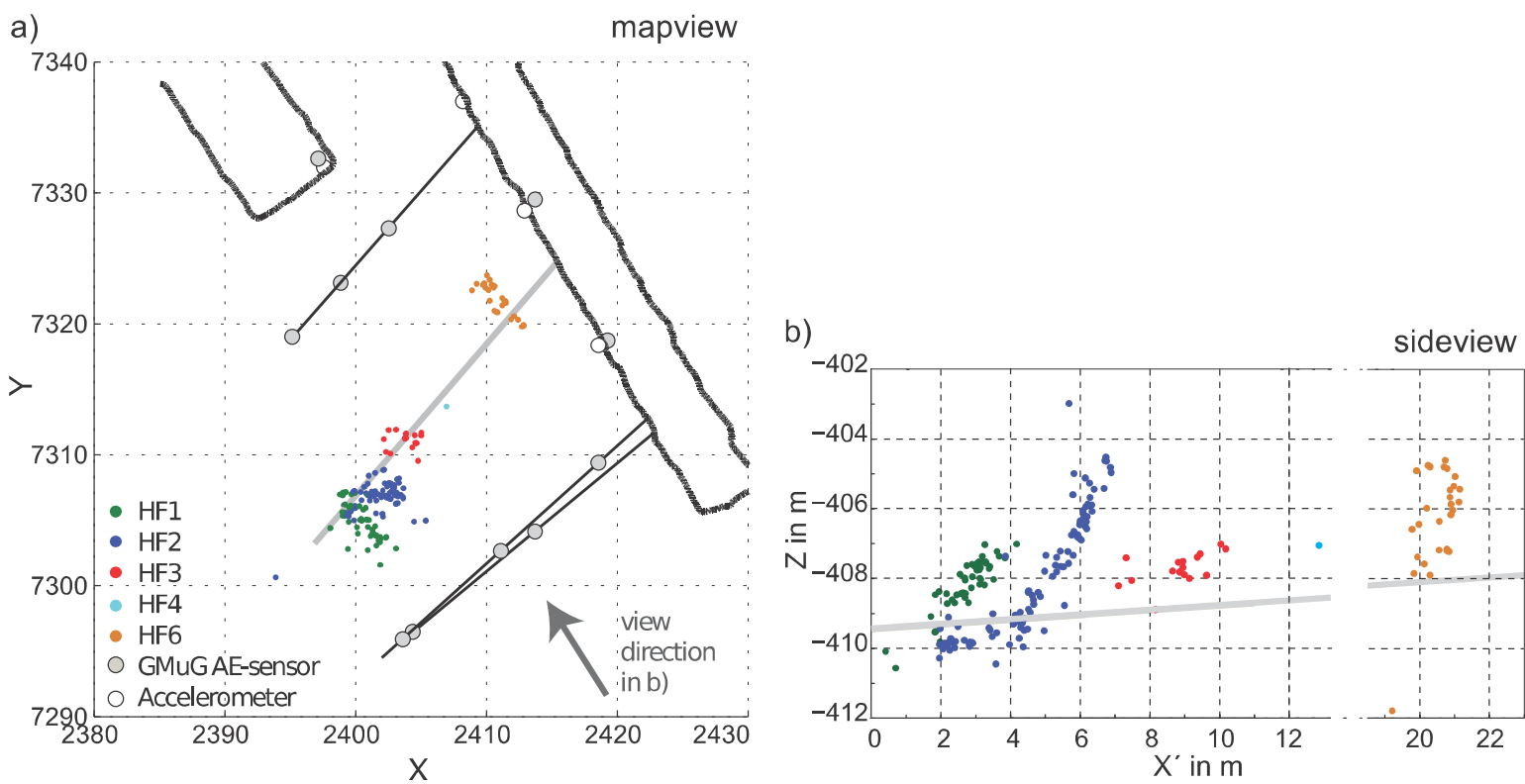

Figure 20. Location of AE events of six HF stimulations (HF1 to HF4 and HF6) presented in a top view (a) and a lateral view (b). For lateral view the coordinate system was rotated in that way to indicate the preferred fracture traces. The solid grey line outlines injection well and the observation boreholes (modified from [43]). All dimensions are given in meter.

Using the continuous data recordings from the Äspö experiment, López-Comino et al. [87] demonstrated that using automated full waveform detection algorithm during post-processing could significantly increase the amount of triggered $\mathrm{AE}$ events. No seismic fracture event was recorded by the microseismic monitoring network or the Wilcoxon accelerometers, although the latter is capable of measuring the frequency range of the observed $\mathrm{AE}$ events. Owing to the small nature of all AE events recorded, not only seismic monitoring in the $\mathrm{kHz}$ range was essential, but also the significantly higher sensitivity of the in situ AE sensors.

A different experiment was conducted at the Grimsel Test Site (GTS) in Switzerland (Figure 21a,b) operated by the Swiss National Cooperative for the Disposal of Radioactive Waste (Nagra). The GTS is located at 1,733 $\mathrm{m}$ above the sea level and has an overburden of 400 to $500 \mathrm{~m}$. Gischig et al. [54] implement in situ AE monitoring for stress determination by HF in the Grimsel site. The so-called in situ stimulation and circulation (ISC) [110] was performed between two tunnels i.e., the VE and the AU tunnel (see Figure 21c), and the injection and monitoring boreholes were mostly drilled from the AU cavern at the southern end of the AU tunnel (Figure 21c). The host rock is the so-called Grimsel granodiorite, which changes into the Central Aar granite about $50 \mathrm{~m}$ north of the experiment volume [111]. The rock mass in the experiment volume is exceptionally intact. The Grimsel test site was monitored using $28 \mathrm{AE}$ sensors (type GMuG MA-Bls-7-70) and four Wilcoxon accelerometers. Most AE sensors were installed on the tunnel wall on polished rock face, while eight AE sensors were installed in a water-filled vertical borehole (Borehole SBH1 in Figure 21c).

For stress determination, a series of hydraulic fracturing tests and overcoring were performed. During hydraulic fracturing, nearly $2000 \mathrm{AE}$ events were recorded with a source-receiver distances smaller than $30 \mathrm{~m}$ that outlined, similar to the Äspö experiment, clearly the fracture plane that extended 
up to $5 \mathrm{~m}$ from the injection point (see Figure 22). Events occurred mostly during the refracturing cycles once a critical injection volume of 0.5 to 1 liter was exceeded and less during the initial fracturing cycle. A comparison of the fracture plane outlined by AE events and stress measurements using an imprint packer and overcoring testing, revealed significant deviations. The imprint packer revealed that fractures initiated at the borehole wall within the foliation plane, but the fracture growth than rotated, as outlined by AE events, in such way that it extends normal to the minimum principal stress. The deviation of the overcoring stress measurement result to the actual fracture plane observed could be explained by using a transversely isotropic elasticity model.

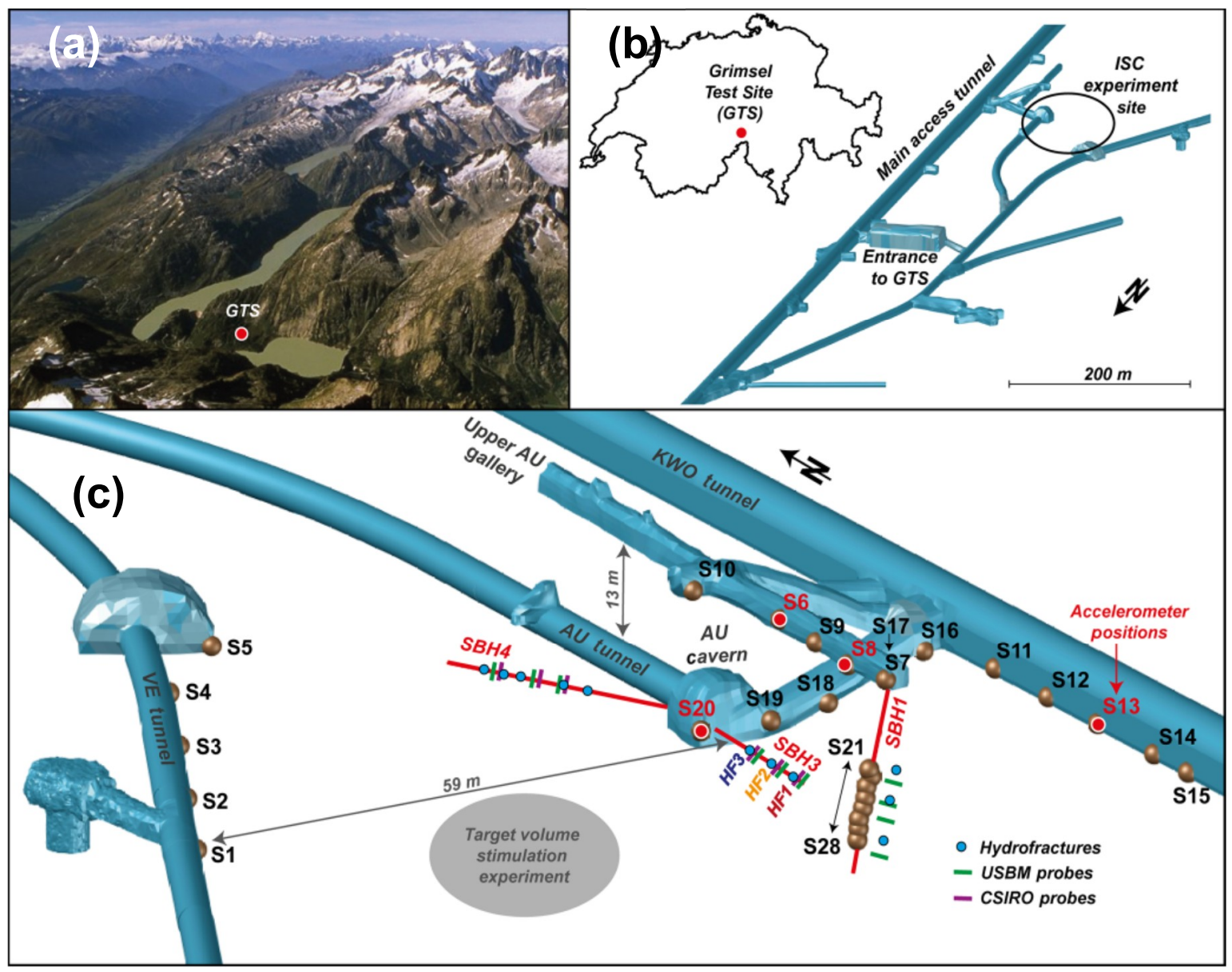

Figure 21. (a,b) Grimsel test site is located in the Bernese Alps in southern Switzerland (see www.grimselstrom.ch). (c) In situ AE monitoring was performed during hydraulic fracturing tests HF1 to HF3 in Borehole SBH3. Positions S1 to S28 mark the location of the AE sensors and accelerometers [88].

The authors conclude that $\mathrm{AE}$ monitoring was crucial for the combined interpretation of the stress characterization results and to maintain meaningful stress estimation.

We summarize that HF routine monitoring using in situ AE monitoring systems becomes feasible for underground production, if sensitive AE sensors for in situ operation are used. Two upcoming projects performing underground medium-scale HF testing will implement AE monitoring accordingly: the enhanced geothermal system (EGS) Collab project's stimulation experiment in Sanford Underground Research Facility in the former Homestake Gold mine, USA [112] and the STIMTEC stimulation experiment in the underground laboratory in the silver mine "Reiche Zeche" in Germany (personal conversation with J. Renner and G. Dresen, 2018) (more details at http://stimtec.rub.de). 


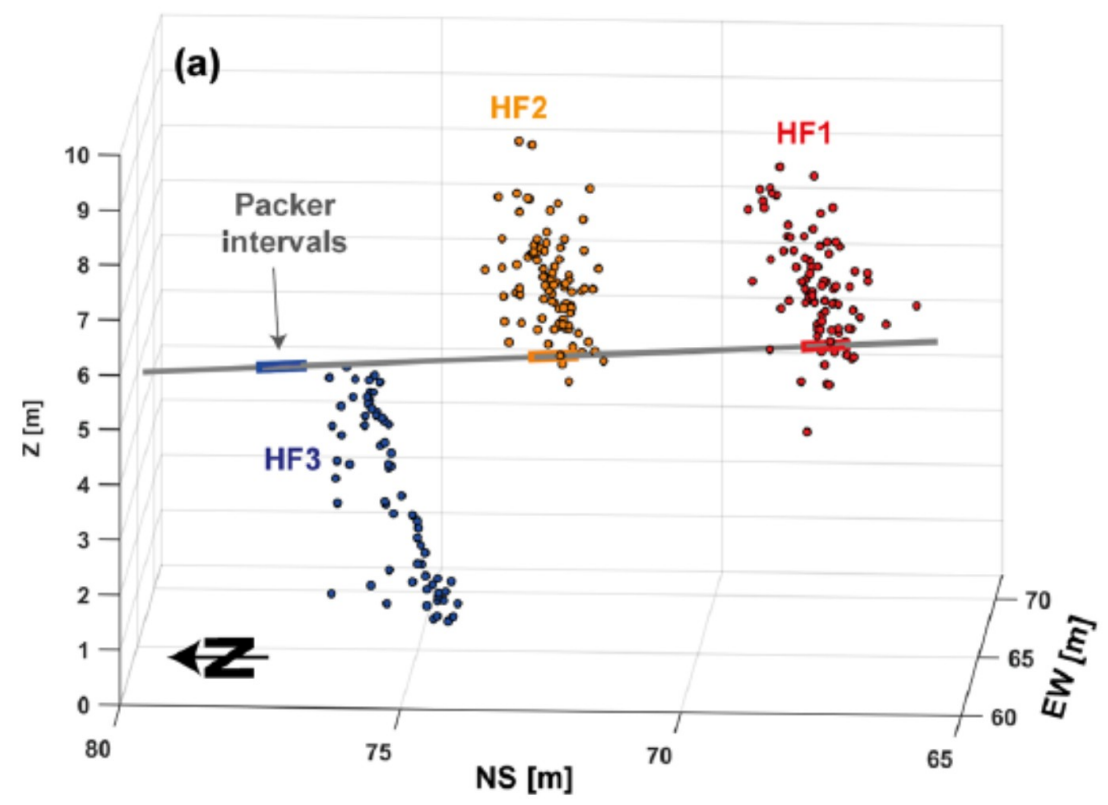

Figure 22. Perspective view of AE events detected during hydraulic fracturing tests HF1 to HF3. The continuous line indicates the injection well with the position of the injection intervals [54].

\section{Concluding Remarks}

In conclusion, this article summarizes the capability of in situ AE monitoring in the context of SHM based on the results of monitoring projects in mines. The in situ AE method is capable of detecting microcracking, in high resolution and sensitivity, which is caused by very small deformation processes at high deviatoric stresses. This means that in situ AE monitoring provides detailed insights into the ongoing deformation processes.

In contrast to in situ AE monitoring, microseismic monitoring is used to measure large-scale deformations in mines, which may cause rock bursts or roof falls. Due to limitations in frequency range and sensitivity, microseismic networks are not able to detect microcracks. Therefore, small AE events are very often not considered for stability assessment and interpretation of geomechanical conditions of the rock. This work clearly shows that in situ AE monitoring is able to detect very small AE events in zones of weakness related to dynamic processes like dilatation. Therefore, in situ AE monitoring is a useful tool to monitor the geomechanical conditions of the host rock.

Real-time processing gives direct information on the location of $\mathrm{AE}$ events as well as on clustering, migration of AE activity or aftershock sequences of microseismic events. Recent advances in computer storage capacity allow recording of continuous data streams with $1 \mathrm{MHz}$ sampling in addition to trigger mode recording, which makes advanced post-processing techniques possible.

The results shown here also demonstrate that monitoring of larger rock volumes with in situ $\mathrm{AE}$ measurements is possible in various rock types. Detections of AE events from distances much greater than $100 \mathrm{~m}$ is possible in rock with low wave attenuation like salt rock or hard rock. In this case, rock volumes far away from the AE network can be monitored. On the other hand, the in situ AE monitoring method is able to identify "aseismic" zones because AE activity is expected during significant damage processes. Finally, in situ AE monitoring is capable of detecting zones in mines where instability may appears long before macroscopic damage becomes visible, which is the objective of SHM.

Author Contributions: G.M. and K.P. wrote the article.

Acknowledgments: The authors thank K. Ono and two anonymous reviewers for their comments and suggestions to improve this article. The authors are grateful to T. Spies and D. Kaiser (BGR in Hannover), G. Kwiatek (GFZ in Potsdam), and H. Moriya (Tohuko University in Sendai) for providing updated figures for this review.

Conflicts of Interest: The authors declare no conflicts of interest. 


\section{References}

1. Condition Monitoring and Diagnostics of Machines_General Guidelines; ISO 17359:2011; Beuth Verlag GmbH: Berlin, Germany, 2011.

2. Cawley, P. Structural health monitoring: Closing the gap between research and industrial deployment. Int. J. Struct. Health Monit. 2018. [CrossRef]

3. Chang, P.C.; Liu, S.C. Recent research in nondestructive evaluation of civil infrastructures. J. Mater. Civil. Eng. 2003, 15, 298-304. [CrossRef]

4. McCrea, A.; Chamberlain, D.; Navon, R. Automated inspection and restoration of steel bridges-A critical review of methods and enabling technologies. Automat. Constr. 2002, 11, 351-373. [CrossRef]

5. Rens, K.L.; Wipf, T.J.; Klaiber, F.W. Review of non-destructive evaluation techniques of civil infrastructure. J. Perform. Constr. Fac. 1997, 11, 152-160. [CrossRef]

6. Chang, P.C.; Flatau, A.; Liu, S.C. Review paper: Health monitoring of civil infrastructure. Struct. Hlth. Monit. 2003, 2, 257-267. [CrossRef]

7. Farrar, C.R.; Doebling, S.W.; Nix, D.A. Vibration-based structural damage identification. Philos. Trans. R. Soc. A 2001, 359, 131-149. [CrossRef]

8. Shih, H.W.; Thambiratnam, D.P.; Chan, T.H.T. Vibration based structural damage detection in flexural members using multi-criteria approach. J. Sound Vib. 2009, 323, 645-661. [CrossRef]

9. Ono, K. Structural Integrity Evaluation Using Acoustic Emission. J. Acoust. Emiss. 2007, 25, 1-20.

10. Ono, K. Review on Structural Health Evaluation with Acoustic Emission. Appl. Sci. 2018, 8, 958. [CrossRef]

11. Eisenblätter, J. The origin of acoustic emission-Mechanisms and models. In Acoustic Emission; Conference in Bad Nauheim, Deutsche Gesellschaft für Metallkunde e.V.: Berlin, Germany, 1980; pp. 189-204.

12. Manthei, G.; Eisenblätter, J. Acoustic Emission in Study of Rock Stability. In Acoustic Emission Testing; Grosse, C.U., Ohtsu, M., Eds.; Springer: Berlin/Heidelberg, Germany, 2008; pp. 239-310.

13. Kwiateka, G.; Plenkers, K.; Martínez-Garzóna, P.; Leonhardt, M.; Zang, A.; Dresen, G. New Insights into Fracture Process through In-Situ Acoustic Emission Monitoring during Fatigue Hydraulic Fracture Experiment in Äspö Hard Rock Laboratory. Procedia Eng. 2017, 191, 618-622. [CrossRef]

14. Stork, A.L.; Butcher, A.C.; Verdon, J.P.; Koe, V.A.; Kendall, J.-M. Geophysical investigations to assess the extent of disturbance in excavated rock faces at hinkley point C. In Proceedings of the 23rd European Meeting of Environmental and Engineering Geophysics, Malmö, Sweden, 3-7 September 2017.

15. Girard, L.; Beutel, J.; Gruber, S.; Hunziker, J.; Lim, R.; Weber, S. A custom acoustic emission monitoring system for harsh environments: Application to freezing-induced damage in alpine rock walls. Geosci. Instrum. Meth. 2012, 1, 155-167. [CrossRef]

16. Kwiatek, G.; Plenkers, K.; Dresen, G.; JAGUARS Research Group. Source Parameters of Picoseismicity Recorded at Mponeng Deep Gold Mine, South Africa: Implications for Scaling Relations. Bull. Seismol. Soc. Am. 2011, 101, 2592-2608. [CrossRef]

17. Bohnhoff, M.; Kwiatek, G.; Dresen, G. Von der Gesteinsprobe bis zur Plattengrenze: Skalenübergreifende Analyse von Bruchprozessen. Syst. Erde 2016, 6, 50-55. (In German)

18. Kwiatek, G.; Bulut, F.; Bohnhoff, M.; Dresen, G. High-resolution analysis of seismicity induced at Berlín geothermal field, El Salvador. Geothermics 2014, 52, 98-111. [CrossRef]

19. Kwiatek, G.; Bohnhoff, M.; Dresen, G.; Schulze, A.; Schulte, T.; Zimmermann, G.; Huenges, E. Microseismicity induced during fluid-injection: A case study from the geothermal site at Groß Schönebeck, North German Basin. Acta Geophys. 2010, 58, 995-1020. [CrossRef]

20. Harrington, R.M.; Kwiatek, G.; Moran, S.C. Self-similar rupture implied by scaling properties of volcanic earthquakes occurring during the 2004-2008 eruption of Mount St. Helens, Washington. J. Geophys. Res. 2015, 120, 4966-4982. [CrossRef]

21. Kwiatek, G.; Martinez Garzon, P.; Dresen, G.; Bohnhoff, M.; Sone, H.; Hartline, C. Effects of long-term fluid injection on induced seismicity parameters and maximum magnitude in northwestern part of The Geysers geothermal field. J. Geophys. Res. 2015, 120, 7085-7101. [CrossRef]

22. Kwiatek, G.; Ben-Zion, Y. Theoretical limits on detection and analysis of small earthquakes. J. Geophys. Res. 2016, 21, 5898-5916. [CrossRef]

23. Madariaga, R. Dynamics of an expanding circular fault. Bull. Seismol. Soc. Am. 1976, 66, 639-666. 
24. Brune, J.N. Tectonic stress and the spectra of seismic shear waves from earthquakes. J. Geophys. Res. 1970, 75, 4997-5009. [CrossRef]

25. Hanks, T.; Kanamori, H. A moment magnitude scale. J. Geophys. Res. 1979, 84, 2348-2350. [CrossRef]

26. Manthei, G.; Eisenblätter, J.; Dahm, T. Moment Tensor Evaluation of Acoustic Emission Sources in Salt Rock. Constr. Build. Mater. 2001, 15, 297-309. [CrossRef]

27. Kwiatek, G.; Marinez-Garzon, P.; Plenkers, K.; Leonhardt, M.; Zang, A.; Specht, S.; Dresen, G.; Bohnhoff, M. Insights into complex sub-decimeter fracturing processes occurring during a water-injection experiment at depth in Äspö Hard Rock Laboratory, Sweden. J. Geophys. Res. Sol. Earth 2018. [CrossRef]

28. Manthei, G.; Eisenblätter, J.; Spies, T. Source Mechanisms of Acoustic Emission Events between huge Underground Cavities in Rock Salt. In Proceedings of the Advances in Acoustic Emission 2007-Proceedings of 6th International Conference on Acoustic Emission, Lake Tahoe, NV, USA, 28 October-2 November 2007; pp. 288-293.

29. Manthei, G. Moment tensor evaluation of acoustic emission sources in rock. In Rock Mechanics and Engineering; Feng, X.-T., Ed.; CRC Press/Balkema: Leiden, The Netherlands, 2017; Volume 4, pp. 478-527, ISBN 9781138027640.

30. Kwiatek, G.; Ben-Zion, Y. Assessment of $P$ and $S$ wave energy radiated from very small shear-tensile seismic events in a deep South African mine. J. Geophys. Res. 2013, 118, 3630-3641. [CrossRef]

31. Kwiatek, G.; Goebel, T.; Dresen, G. Seismic moment tensor and b value variations over successive seismic cycles in laboratory stick-slip experiments. Geophys. Res. Lett. 2014, 41, 5838-5846. [CrossRef]

32. Lockner, D.A. The Role of Acoustic Emission in the Study of Rock. Int. J. Rock Mech. Min. Sci. 1993, 30, 883-899. [CrossRef]

33. Yabe, Y.; Philipp, J.; Nakatani, M.; Morema, G.; Naoi, M.; Kawakata, H.; Igarashi, T.; Dresen, G.; Ogasawara, H.; JAGUARS Research Group. Observation of numerous aftershocks of an 1.9 earthquake with an AE network installed in a deep gold mine in South Africa. Earth Planets Space 2009, 61, e49-e52. [CrossRef]

34. Moriya, H.; Naoi, M.; Nakatani, M.; van Aswegen, G.; Murakami, O.; Kgarume, T.; Ward, A.K.; Durrheim, R.J.; Philipp, J.; Yabe, Y.; et al. Delineation of large localized damage structures forming ahead of an active mining front by using advanced acoustic emission mapping techniques. Int. J. Rock Mech. Min. 2015, 79, 157-165. [CrossRef]

35. Manthei, G.; Eisenblätter, J.; Spies, T. Determination of Wave Attenuation in Rock Salt in the Frequency Range 1-100 kHz using Located Acoustic Emission Events. J. Acoust. Emiss. 2006, 24, 179-186.

36. Plenkers, K.; Kwiatek, G.; Nakatani, M.; Dresen, G.; JAGUARS Research Group. Observation of Seismic Events with Frequencies f $>25 \mathrm{kHz}$ at Mponeng Gold Mine, South Africa. Seism. Res. Lett. 2010, 81, 467-479. [CrossRef]

37. Spies, T.; Eisenblätter, J. Acoustic emission investigation of microcrack generation at geological boundaries. Eng. Geol. 2001, 61, 181-188. [CrossRef]

38. Philipp, J.; Plenkers, K.; Gärtner, G.; Teichmann, L. On the potential of In-Situ Acoustic Emission (AE) technology for the monitoring of dynamic processes in salt mines. In Proceedings of the Conference on Mechanical Behavior of Salt, South Dakota School of Mines and Technology, Mechanical Behavior of Salt VIII, Rapid City, SD, USA, 26-28 May 2015; Lance, R., Mellegard, K., Hansen, F., Eds.; CRC Press/Balkema: Leiden, The Netherlands, 2015; pp. 89-98, ISBN 9781138028401.

39. Spies, T.; Hesser, J.; Eisenblätter, J.; Eilers, J. Measurements of acoustic emission during backfilling of large excavations. In Proceedings of the 6th International Symposium on Rockbursts and Seismicity Mines (RaSiM6), Perth, Australia, 9-11 March 2005; pp. 379-384.

40. Becker, D.; Cailleau, B.; Dahm, T.; Shapiro, S.; Kaiser, D. Stress triggering and stress memory observed from acoustic emission records in a salt mine. Geophys. J. Int. 2010, 182, 933-948. [CrossRef]

41. Eisenblätter, J.; Manthei, G.; Meister, D. Monitoring of Microcrack Formation around Galleries in Salt Rock. In Proceedings of the Sixth Conference on Acoustic Emission/Microseismic Activity in Geologic Structures and Materials, Pennsylvania State University, University Park, PA, USA, 9-11 June 1998; Hardy, H.R., Jr., Ed.; Trans Tech Publications: Clausthal-Zellerfeld, Germany, 1998; pp. 227-243.

42. Manthei, G.; Philipp, J.; Dörner, D. Acoustic Emission monitoring around gas-pressure loaded boreholes in rock salt. In Mechanical Behavior of Salt VII; Berest, P.B., Ghoreychi, M., Hadj-Hassen, F., Tijani, M., Eds.; Taylor \& Francis (Balkema): London, UK, 2012; pp. 185-192, ISBN 9780415621229. 
43. Zang, A.; Stephansson, O.; Stenberg, L.; Plenkers, K.; Specht, S.; Milkereit, K.; Schill, E.; Kwiatek, G.; Dresen, G.; Zimmermann, G.; et al. Hydraulic fracture monitoring in hard rock at $410 \mathrm{~m}$ depth with an advanced fluid-injection protocol and extensive sensor array. Geophys. J. Int. 2017, 208, 790-813. [CrossRef]

44. Hsu, N.N.; Breckenridge, F. Characterization of acoustic emission sensors. Mater. Eval. 1981, 39, 60-68.

45. Theobald, P.D.; Esward, T.J.; Dowson, S.P.; Preston, R.C. Acoustic emission transducers development of a facility for traceable out-of-plane displacement calibration. Ultrasonics 2005, 43, 343-350. [CrossRef] [PubMed]

46. Kim, K.Y.; Castagnede, B.; Sachse, W. Miniaturized capacitive transducer for detection of broadband ultrasonic signals. Rev. Sci. Instrum. 1989, 60, 2785-2788. [CrossRef]

47. Manthei, G. Characterization of Acoustic Emission Sources in a Rock Salt Specimen under Triaxial Compression. Bull. Seismol. Soc. Am. 2005, 95, 1674-1700. [CrossRef]

48. McLaskey, G.; Glaser, S. Acoustic emission sensor calibration for absolute source measurements. J. Nondest. Eval. 2012, 31, 157-168. [CrossRef]

49. Ono, K. Critical examination of ultrasonic transducer characteristics and calibration methods. Res. Nondestruct. Eval. 2017. [CrossRef]

50. Ono, K. Calibration Methods of Acoustic Emission Sensors. Materials 2016, 9, 508. [CrossRef] [PubMed]

51. Manthei, G. Characterization of AE Sensors for Moment Tensor Analysis. In Proceedings of the International Acoustic Emission Conference, Kumamoto University, Kumamoto, Japan, 12-15 September 2010; pp. $19-24$.

52. Plenkers, K.; Schorlemmer, D.; Kwiatek, G.; JAGUARS Research Group. On the Probability of Detecting Picoseismicity. Bull. Seismol. Soc. Am. 2011, 101, 2579-2591. [CrossRef]

53. Naoi, M.; Nakatani, M.; Horiuchi, S.; Yabe, Y.; Philipp, J.; Kgarume, T.; Morema, G.; Khambule, S.; Masakale, T.; Ribeiro, L.; et al. Frequency-magnitude distribution of $-3.7 \leq \mathrm{Mw} \leq 1$ mining-induced earthquakes around a mining front and b-value invariance with post-blast time. Pure Appl. Geophys. 2013, 171, 2665-2684. [CrossRef]

54. Gischig, V.S.; Doetsch, J.; Maurer, H.; Krietsch, H.; Amann, F.; Evans, K.F.; Nejati, M.; Jalali, M.; Valley, B.; Obermann, A.C.; et al. On the link between stress field and small-scale hydraulic fracture growth in anisotropic rock derived from microseismicity. Solid Earth 2018, 9, 39-61. [CrossRef]

55. Kwiatek, G.; Plenkers, K.; Nakatani, M.; Yabe, Y.; Dresen, G.; JAGUARS Research Group. Frequency-magnitude characteristics down to magnitude -4.4 for induced seismicity recorded at Mponeng gold mine, South Africa. Bull. Seismol. Soc. Am. 2010, 100, 1167-1173. [CrossRef]

56. Eisenblätter, J.; Spies, T. Ein Magnitudenma $\beta$ für Schallemissionsanalyse und Mikroakustik. In Deutsche Gesellschaft für zerstörungsfreie Prüfung; 12. Kolloquium Schallemission; DGZfP Berichtsband: Jena, Germany, 2000; pp. 29-41. (In German)

57. Sasaki, S.; Ishida, T.; Kanagawa, T. Source location and focal mechanisms of AE events during the hydraulic fracturing. In CRIEPI Rep. U86032; Central Research Institute of Electric Power Industry: Abiko, Japan, 1987.

58. Ohtsu, M. Simplified Moment Tensor Analysis and Unified Decomposition of Acoustic Emission Sources: Application to In Situ Hydrofracturing Test. J. Geophys. Res. 1991, 96, 6211-6221. [CrossRef]

59. Young, R.P.; Collins, D.S. Monitoring an experimental tunnel seal in granite using acoustic emission and ultrasonic velocity. In Rock Mechanics for Industry; Amadei, B., Kranz, R.L., Scott, G.A., Smeallie, P.H., Eds.; Balkema: Leiden, The Netherlands, 1999; pp. 869-876.

60. Young, R.P.; Hazzard, J.F.; Pettitt, W.S. Seismic and micromechanical studies of rock fracture. Geophys. Res. Lett. 2000, 1767-1770. [CrossRef]

61. Young, R.P.; Collins, D.S. Seismic studies of rock fracture at the Underground Research Laboratory, Canada. Int. J. Rock Mech. 2001, 38, 787-799. [CrossRef]

62. Collins, D.S.; Pettitt, W.S.; Young, R.P. High-resolution mechanics of a micro-earthquake sequence. Pure Appl. Geophys. 2002, 159, 197-219. [CrossRef]

63. Young, R.P.; Collins, D.S.; Reyes-Montes, J.M.; Baker, C. Quantification and interpretation of seismicity. Int. J. Rock Mech. 2004, 41, 1317-1327. [CrossRef]

64. Dahm, T.; Manthei, G.; Eisenblätter, J. Relative Moment Tensors of Thermally Induced Microcracks in Salt Rock. Tectonophysics 1998, 289, 61-74. [CrossRef] 
65. Manthei, G.; Eisenblätter, J.; Salzer, K. Acoustic Emission Studies on Thermally and Mechanically Induced Cracking in Salt Rock. In Proceedings of the Sixth Conference on Acoustic Emission/Microseismic Activity in Geologic Structures and Materials, Pennsylvania State University, University Park, PA, USA, 9-11 June 1998; Hardy, H.R., Jr., Ed.; Trans Tech Publications: Clausthal-Zellerfeld, Germany, 1998; pp. 245-265.

66. Dahm, T.; Manthei, G.; Eisenblätter, J. Automated Moment Tensor Inversion to Estimate Source Mechanism of Hydraulically Induced Micro-Seismicity in Salt Rock. Tectonophysics 1999, 306, 1-17. [CrossRef]

67. Manthei, G.; Eisenblätter, J.; Kamlot, P. Stress measurements in salt mines using a special hydraulic fracturing borehole tool. In Proceedings of the International Symposium on Geotechnical Measurements and Modelling, Karlsruhe, Germany, 23-26 September 2003; pp. 355-360.

68. Pettitt, W.S.; Baker, C.; Young, R.P. Using acoustic emission and ultrasonic techniques for assessment of damage around critical engineering structures. In Proceedings of 5th North American Rock Mechanics Symposium; University of Toronto Press: Toronto, ON, Canada, 2002; pp. 1161-1170.

69. Spies, T.; Hesser, J.; Eisenblätter, J.; Eilers, G. Monitoring of the rockmass in the final repository Morsleben: Experiences with acoustic emission measurements and conclusions. In Proceedings of the DisTec 2004, Berlin, Germany, 26-28 April 2004; pp. 303-311.

70. Manthei, G.; Eisenblätter, J.; Spies, T.; Eilers, G. Source Parameters of Acoustic Emission Events in Salt Rock. J. Acoust. Emiss. 2001, 19, 100-108.

71. Köhler, D.; Spies, T.; Dahm, T. Seismicity patterns and variation of the frequency-magnitude distribution of microcracks in salt. Geophys. J. Int. 2009, 179, 489-499. [CrossRef]

72. Becker, D.; Cailleau, B.; Kaiser, D.; Dahm, T. Macroscopic Failure Processes at Mines Revealed by Acoustic Emission (AE) Monitoring. Bull. Seismol. Soc. Am. 2014, 104, 1785-1801. [CrossRef]

73. Nakatani, M.; Yabe, Y.; Philipp, J.; Morema, G.; Stanchits, S.; Dresen, G. Acoustic emission measurements in a deep gold mine in South Africa: project overview and some typical waveforms. Seismol. Res. Lett. 2008, 79, 311.

74. Naoi, M.; Nakatani, M.; Yabe, Y.; Kwiatek, G.; Igarashi, T.; Plenkers, K. Twenty thousand aftershocks of a very small (M 2) earthquake and their relation to the mainshock rupture and geological structures. Bull. Seismol. Soc. Am. 2011, 101, 2399-2407. [CrossRef]

75. Davidsen, J.; Kwiatek, G. Earthquake Interevent Time Distribution for Induced Micro-, Nano-, and Picoseismicity. Phys. Rev. Lett. 2013, 110. [CrossRef] [PubMed]

76. Davidsen, J.; Kwiatek, G.; Dresen, G. No Evidence of Magnitude Clustering in an Aftershock Sequence of Nano- and Picoseismicity. Phys. Rev. Lett. 2012, 108. [CrossRef] [PubMed]

77. Ziegler, M.; Reiter, K.; Heidbach, O.; Zang, A.; Kwiatek, G.; Stromeyer, D.; Dahm, T.; Dresen, G.; Hofmann, G. Mining-Induced Stress Transfer and Its Relation to a Mw 1.9 Seismic Event in an Ultra-deep South African Gold Mine. Pure Appl. Geophys. 2015, 172, 2557-2570. [CrossRef]

78. Yabe, Y.; Nakatani, M.; Naoi, M.; Philipp, J.; Janssen, C.; Watanabe, T.; Katsura, T.; Kawakata, H.; Dresen, G.; Ogasawara, H. Nucleation process of an M2 earthquake in a deep gold mine in South Africa inferred from on-fault foreshock activity. J. Geophys. Res. Sol. Earth 2015, 120, 5574-5594. [CrossRef]

79. Kozłowska, M.; Orlecka-Sikora, B.; Kwiatek, G.; Boettcher, M.S.; Dresen, G. Nanoseismicity and picoseismicity rate changes from static stress triggering caused by a Mw 2.2 earthquake in Mponeng gold mine, South Africa. J. Geophys. Res. Sol. Earth 2015, 120, 290-307. [CrossRef]

80. Dörner, D.; Philipp, J.; Manthei, G.; Popp, T. Monitoring of AE activity around a large-diameter borehole in rock salt. In Proceedings of the International Acoustic Emission Conference, Progress in Acoustic Emission XVI, Okinawa, Japan, 21-24 October 1986; pp. 187-192.

81. Popp, T.; Minkley, W.; Wiedemann, M.; Salzer, K.; Dörner, D. Gas pressure effects on salt—the large scale in-situ test Merkers. In Proceedings of the Conference on Mechanical Behavior of Salt, South Dakota School of Mines and Technology, Mechanical Behavior of Salt VIII, Rapid City, SD, USA, 26-28 May 2015; Lance, R., Mellegard, K., Hansen, F., Eds.; CRC Press/Balkema: Leiden, The Netherlands, 2015; pp. 127-136.

82. Plenkers, K.; Philipp, P.; Dörner, D.; Minkley, W.; Popp, T.; Wiedemann, M. Observation of seismic and aseismic rock behavior during large-scale loading experiment. In Proceedings of the Mechanical Behavior of Salt IX, Hannover, Germany, 12-14 September 2018.

83. Le Gonidec, Y.; Schubnel, A.; Wassermann, J.; Gibert, D.; Nussbaum, C.; Kergosien, B.; Sarout, J.; Maineult, A.; Guéguen, Y. Field-scale acoustic investigation of a damaged anisotropic shale during a gallery excavation. Int. J. Rock Mech. Min. 2012, 51, 136-148. [CrossRef] 
84. Naoi, M.; Nakatani, M.; Otsuki, K.; Yabe, Y.; Kgarume, T.; Murakami, O.; Masakale, T.; Ribeiro, L.; Ward, A.; Moriya, H.; et al. Steady activity of microfractures on geological faults loaded by mining stress. Tectonophysics 2015, 100-114. [CrossRef]

85. Naoi, M.; Nakatani, M.; Kgarume, T.; Khambule, S.; Masakale, T.; Ribeiro, L.; Philipp, J.; Horiuchi, S.; Otsuki, K.; Miyakawa, K.; et al. Quasi-static slip patch growth to $20 \mathrm{~m}$ on a geological fault inferred from acoustic emissions in a South African gold mine. J. Geophys. Res. 2015, 120, 1692-1707. [CrossRef]

86. Naoi, M.; Nakatani, M.; Igarashi, T.; Otsuki, K.; Yabe, Y.; Kgarume, T.; Murakami, O.; Masakale, T.; Ribeiro, L.; Ward, A.; et al. Unexpectedly frequent occurrence of very small repeating earthquakes $(-5.1 \leq \mathrm{Mw} \leq-3.6)$ in a South African gold mine: Implications for monitoring intraplate faults. J. Geophys. Res. Sol. Earth 2015, 120, 8478-8493. [CrossRef]

87. López-Comino, J.A.; Heimann, S.; Cesca, S.; Milkereit, C.; Dahm, T.; Zang, A. Automated full waveform detection and location algorithm of acoustic emissions from hydraulic fracturing experiment. Proc. Eng. 2017, 191, 697-702. [CrossRef]

88. Jalali, M.; Gischig, V.; Doetsch, J.; Näf, R.; Krietsch, H.; Klepikova, M.; Amann, F.; Giardini, D. Transmissivity changes and microseismicity induced by small-scale hydraulic fracturing tests in crystalline rock. Geophys. Res. Lett. 2018, 45, 1-9. [CrossRef]

89. Allen, R. Automatic phase pickers: their present use and future prospects. Bull. Seismol. Soc. Am. 1982, 72, 225-242.

90. Kamlot, P.; Günther, R.-M.; Stockmann, N.; Gärtner, G. Modeling of strain softening and dilatancy in the mining system of the southern flank of the Asse II mine. In Mechanical Behavior of Salt VII; Berest, P.B., Ghoreychi, M., Hadj-Hassen, F., Tijani, M., Eds.; Taylor \& Francis (Balkema): London, UK, 2012; pp. 327-336.

91. Kamlot, P.; Weise, D.; Gärtner, G.; Teichmann, L. Drift sealing in the Asse II mine as a component of the emergency concept-Assessment of the hydro-mechanical functionality. In Mechanical Behavior of Salt VII; Berest, P.B., Ghoreychi, M., Hadj-Hassen, F., Tijani, M., Eds.; Taylor \& Francis (Balkema): London, UK, 2012; pp. 479-489.

92. Kaiser, D.; Spies, T.; Schmitz, H. Mikroakustisches Monitoring in Bergwerken zur Bewertung aktueller Rissprozesse. In Proceedings of the GeoMonitoring 2013, Hannover, Germany, 14-15 March 2013; Sörgel, U., Schack, L., Eds.; 2013; pp. 39-55. (In German)

93. Lavrov, A.; Vervoort, A.; Filimonov, Y.; Wevers, M.; Mertens, J. Acoustic emission in host-rock material for radioactive waste disposal: comparison between clay and rock salt. Bull. Eng. Geol. Environ. 2002, 61, 379-387. [CrossRef]

94. Waldhauser, F.; Ellsworth, W.L. A double-difference earthquake location algorithm: method and application to the Northern Hayward Fault, California. Bull. Seismol. Soc. Am. 2000, 90, 1353-1368. [CrossRef]

95. Ortlepp, W.D. Observation of mining-induced faults in an intact rock mass at depth. Int. J. Rock Mech. Min. 2012, 37, 423-436. [CrossRef]

96. van Aswegen, G. Forensic rock mechanics, Ortlepp shears and other mining induced structures. In Proceedings of the 8th International Symposium on Rockbursts and Seismicity in Mines (RaSiM8), St. Petersburg and Moscow, Russia, 1-8 September 2013; Balkema: Rotterdam, The Netherlands, 2013; pp. 1-19.

97. Heesakkers, V.; Murphy, S.K.; Reches, Z. Earthquake Rupture at Focal Depth, Part I: Structure and Rupture of the Pretorius Fault, TauTona Mine, South Africa. Pure Appl. Geophys. 2011, 168, 2395-2425. [CrossRef]

98. McGarr, A. Violent deformation of rock near deep-level, tabular excavation-seismic events. Bull. Seismol. Soc. Am. 1971, 61, 1453-1466.

99. Naoi, M.; Nakatani, M.; Yabe, Y.; Philipp, J.; JAGUARS Research Group. Very high frequency AE $(<200 \mathrm{kHz})$ and micro seismicity observation in a deep South African gold mine-Evaluation of the acoustic properties of the site by in-situ transmission test. Seismol. Res. Lett. 2008, 79, 330.

100. Stacey, T.R.; Wesseloo, J. In situ stresses in mining areas in South Africa. J. S. Afr. Inst. Min. Metall. 1998, 365-368.

101. Haimson, B.C.; Cornet, F.H. ISRM Suggested Methods for rock stress estimation-Part 3: hydraulic fracturing (HF) and/or hydraulic testing of pre-existing fractures (HTPF). Int. J. Rock Mech. Min. 2003, 40, 1011-1020. [CrossRef]

102. Kaiser, P.K.; Valley, B.; Dusseault, M.B.; Duff, D. Hydraulic fracturing mine back trials—Design rationale and project status. In Proceedings ISRM International Conference for Effective and Sustainable Hydraulic Fracturing; International Society for Rock Mechanics, IntechOpen Limited: London, UK, 2013. [CrossRef] 
103. Warpinski, N.R.; Mayerhofer, M.; Agarwal, K.; Du, J. Hydraulic-fracture geomechanics and microseismic-source mechanisms. SPE J. 1992, 18, 766-780. [CrossRef]

104. Economides, M.J.; Nolte, K.G.; Ahmed, U.; Schlumberger, D. Reservoir Stimulation; Wiley: Chichester, UK, 2000.

105. Häring, M.O.; Schanz, U.; Ladner, F.; Dyer, B.C. Characterisation of the Basel 1 enhanced geothermal system. Geothermics 2008, 37, 469-495. [CrossRef]

106. Schindler, M.; Nami, P.; Schellschmidt, R.; Teza, D.; Tischner, T. Summary of hydraulic stimulation operations in the $5 \mathrm{~km}$ deep crystalline HDR/EGS reservoir at Soultz-sous-Forêts. In Proceedings of the 33rd Workshop on Geothermal Reservoir Engineering, Stanford, CA, USA, 28-30 January 2008; pp. 325-333.

107. Jeffrey, R.G. Hydraulic Fracturing of Ore Bodies. U.S. Patent No. 6,123,394, 2000.

108. Niitsuma, H.; Nagano, K.; Hisamatsu, K. Analysis of acoustic emission from hydraulically induced tensile fracture of rock. J. Acoust. Emiss. 1993, 11, S1-S18.

109. Guglielmi, Y.; Cappa, F.; Avouac, J.P.; Henry, P.; Elsworth, D. Seismicity triggered by fluid injection-induced aseismic slip. Science 2015, 348, 1224-1226. [CrossRef] [PubMed]

110. Amann, F.; Gischig, V.; Evans, K.; Doetsch, J.; Jalali, R.; Valley, B.; Krietsch, H.; Dutler, N.; Villiger, L.; Brixel, B.; et al. The seismo-hydro-mechanical behaviour during deep geothermal reservoir stimulations: Open questions tackled in a decameterscale in-situ stimulation experimen. Solid Earth 2018, 9, 115-137. [CrossRef]

111. Keusen, H.; Ganguin, J.; Schuler, P.; Buletti, M. Grimsel Test Site: Geology, Report; Nationale Genossenschaft für die Lagerung Radioaktiver Abfälle (NAGRA): Wettingen, Switzerland, 1989.

112. Morris, J.P.; Dobson, P.; Knox, H.; Ajo-Franklin, J.; White, M.D.; Fu, P.; Burghardt, J.; Kneafsey, T.J.; Blankenship, D.; EGS Collab Team. Experimental Design for Hydrofracturing and Fluid Flow at the DOE Collab Testbed. In Proceedings of the 43rd Workshop on Geothermal Reservoir Engineering Stanford University, Stanford, CA, USA, 12-14 February 2018.

(C) 2018 by the authors. Licensee MDPI, Basel, Switzerland. This article is an open access article distributed under the terms and conditions of the Creative Commons Attribution (CC BY) license (http://creativecommons.org/licenses/by/4.0/). 